\title{
CORRELAÇÕES ENTRE A CULTURA E O COMÉRCIO INTERNACIONAL: UMA ANÁLISE DAS PERSPECTIVAS BRASILEIRAS NA ATUALIDADE
}

\author{
Maria Fortunata Lorigiola Harima \\ Graduada em Tecnologia em Comércio Exterior pelo Instituto Federal de Educação, \\ Ciência e Tecnologia do Rio Grande do Norte. E-mail: fortunata.lorigiola@gmail.com. \\ Elisângela Cabral de Meireles \\ Graduada em Ciências Econômicas-UFRN, esp. em Economia Regional, Comércio \\ Exterior e Globalização-UFRN, mestre em Administração (Gestão e Políticas Públicas) \\ UFRN , Professora do IFRN (Comércio Exterior e Economia) e Professora Orientadora da \\ Base de Pesquisa "Análise do Mercado Exportador do Rio Grande do Norte (IFRN). \\ E-mail- elisangela@cefetrn.br
}

\begin{abstract}
RESUMO
Este trabalho teve como objetivo principal pesquisar as relações econômicas relacionadas com a cultura. A pesquisa foi justificada pela necessidade de avaliar a importância que o setor da cultura apresenta nas relações internacionais, comerciais brasileiras, tanto de ordem econômica quanto de ordem desenvolvimentista, no que tange à produção sustentável de riqueza econômica e cultural. A metodologia aplicada neste trabalho consistiu na busca e pesquisa exploratória descritiva por meio de consultas a livros, artigos e revistas. Como também foi realizado levantamento de dados secundários utilizando a exemplo de websites. O desenvolvimento foi pautado em informações que evidenciam a cultura como forte aliada ao desenvolvimento econômico, ocupando em alguns países posição de destaque na geração de emprego e renda, e tratada como substituta de setores industriais, que até pouco tempo eram os principais meios de produção e geração de riqueza desses países, como também um bem que agrega valor aos produtos produzidos, favorecendo a criação de uma boa imagem para o país.
\end{abstract}

Palavras-chave: Economia da cultura, Relações culturais econômicas, Desenvolvimento econômico.

\section{CORRELATIONS BETWEEN CULTURE AND INTERNATIONAL COMMERCE: AN ANALYSIS OF THE BRAZILIAN PERSPECTIVES IN THE PRESENT}

\begin{abstract}
This study has as main objective research the economic relations related to culture. The development importance that the sector of culture presented in international relations, Brazilian trade, both in the economic order of a developmental, in terms of sustainable production of economic and cultural wealth. The methodology applied in this work was to search and exploratory research descriptive through consultations with books, articles and magazines. As the survey was conducted using secondary data such as websites. The development was based on information that highlight the culture as a strong ally to economic development in some countries occupying a prominent position in the generation of employment and income, and treated as a substitute for industrial sectors, which until recently were the main means of production and generation of wealth in these countries, as well as a well that adds value to products, creating an invisible to the image of the country.
\end{abstract}


Key-words: Economy of culture, Cultural and economic relations, Economic development.

\section{CORRELAÇÕES ENTRE A CULTURA E O COMÉRCIO INTERNACIONAL: UMA ANÁLISE DAS PERSPECTIVAS BRASILEIRAS NA ATUALIDADE}

\section{INTRODUÇÃO}

O Brasil tem historicidade cultural e por essa historicidade tem muito que estabelecer dentro e além do seu território. Porém, apresenta fragilidades na capacidade de difundir nossa vasta cultura internamente, o que dirá externamente.

É exatamente por perceber essas fragilidades que esse trabalho objetiva avaliar as possibilidades nas relações econômicas relacionadas com a cultura.

Efetivamente, o Brasil vem ganhando espaço econômico, comercial e político na cena mundial, tornando-se entre outros participantes do grupo de países em desenvolvimento o G20, do BRIC (Brasil, Rússia, Índia e China) e dos grandes fóruns mundiais. Integra de forma atuante a Organização Mundial do Comércio (OMC), no qual é signatário da maioria dos acordos.

Historicamente, caracteriza-se como um país pacífico, e de boas relações diplomáticas. Contudo, há de se destacar que o comércio internacional que o Brasil pratica tem sido centrado na Balança Comercial, portanto em elementos tangíveis. A cultura, elemento importante, mas de alta intangibilidade, ainda possui, no Brasil, um tratamento comercial frágil, sob o prisma nacional e internacional. Daí porque percebe-se que há uma maior aproximação das relações culturais, quando destinadas à amostra exterior, centradas nas relações institucionais diplomáticas, que nem sempre tem fins lucrativos.

Buscou-se, então, iniciar esse trabalho, justificado pela importância que o setor da cultura apresenta nas relações internacionais, comerciais brasileiras, tanto de ordem econômica quanto de ordem desenvolvimentista, no que tange à produção sustentável de riqueza econômica e cultural.

Procurando, manter a relação entre a cultura e o setor acadêmico, e identificando as relações que envolvem cultura e economia, e aproveitando a oportunidade de conscientizar de que é possível promover crescimento sustentável por meio da cultura, seja nas negociações comerciais internacionais, seja por meio da produção cultural, ou ainda por meio de expressão cultural, foram então estabelecidas as bases para o presente estudo

A concepção de cultura adotada neste estudo está relacionada com as atividades econômicas geradoras de bens e serviços. O setor cultural foi definido tomando-se como referência inicial a definição da Organização das Nações Unidas para a Educação, a Ciência e a Cultura (UNESCO) sobre as atividades culturais relacionadas. 
[...] à criação, produção, e comercialização de conteúdos que são intangíveis e culturais em sua natureza. Estes conteúdos estão protegidos pelo direito autoral e podem tomar a forma de bens e serviços. São indústrias em trabalho e conhecimento e que estimulam a criatividade e incentivam a inovação dos processos de produção e comercialização (INFORME, 2004, p. 416).

O papel fundamental da cultura pode beneficiar o desenvolvimento de outras políticas públicas, acentuando sua eficiência, tanto nos aspectos econômicos, como nas dimensões social e ambiental (RUIZ, 2003).

A questão referente à cultura em vários aspectos aproxima pessoas e países quando é vista como patrimônio comum, como também um instrumento de acesso a outros povos e costumes e de inserção em novos mercados.

A relação entre cultura e as demais formas de expressão do homem (tecnológica, econômica, política, dentre outras não menos importantes), ao que tudo indica, vem ocorrendo ao longo do tempo sem que haja uma identificação mais precisa do impacto positivo causado pela influência cultural.

Destaca-se nesse contexto, que a cultura de modo geral, sempre esteve presente em tudo, como imagem de um bem tangível ou por meio da própria cultura, ressaltando que possui em si caráter estritamente intangível.

Como se dá o reconhecimento da importância da cultura nos mais diversos setores da sociedade, como esse interesse se manifesta?

Na história cultural é conhecida a tradição de apoio às artes e cultura por parte de atores políticos e econômicos importantes, como príncipes ou governantes, empresários, financistas ou amadores esclarecidos. Na atualidade, com a organização e apoio de Estado, abrem-se possibilidades de intervenção sistemática para a criação de ocupações e geração de renda relacionada às atividades culturais, industriais ou não, considerando as possibilidades de desenvolvimento de regiões menos dinâmicas economicamente (SILVA, 2007).

Assim sendo, percebeu-se uma estreita relação entre o desenvolvimento econômico e a cultura, por intermédio da produção cultural, seja ela artística provedora de recursos econômicos, como também pelos hábitos e costumes relacionados às negociações comerciais, envolvendo países e suas relações diplomáticas.

Para o desenvolvimento deste trabalho, foram explorados os pontos fortes proporcionados pela relação econômica cultural para a comunidade de um modo geral, procurando salientar a promoção do desenvolvimento econômico por meio dos recursos culturais disponíveis.

A metodologia aplicada neste trabalho consistiu na busca e pesquisa exploratória descritiva por meio de consultas a livros, artigos e revistas. Como também foi realizado levantamento de dados secundários utilizando a exemplo de websites.

A seleção de artigos científicos na Internet foi uma das fontes para a busca de materiais mais atualizados no momento da confecção desse trabalho, sendo, portanto de relevante importância para a atualização das informações. 
De maneira geral, o conhecimento científico se prendeu aos fatos e teve referência empírica. O conhecimento empírico foi a estrutura para se chegar ao conhecimento científico.

No desenvolvimento desse trabalho foram realizadas buscas incessantemente por fontes onde pudessem ser encontrados dados relativos ao assunto cultura enquanto promotora de desenvolvimento econômico.

O tema escolhido para ser desenvolvido, apresentou certa aridez de fontes, o que em momento algum foi motivo para desistência do tema, pelo ao contrario, representou um desafio estimulante a ser concluído com muita dedicação para a finalização da pesquisa aqui apresentada.

\section{CONTRIBUIÇÃO DA CULTURA NO DESENVOLVIMENTO GLOBAL}

Nesta seção é tratada a definição do conceito de cultura, as possibilidades de contribuição que a cultura poderá oferecer ao desenvolvimento sustentável, como também, aborda aspectos preliminares da pesquisa no que tange as relações internacionais dentro do tema cultura como economia. As relações internacionais comerciais e econômicas são correlacionadas com a possível contribuição da cultura no que diz respeito ao desenvolvimento sustentável e a preservação da identidade cultural de cada nação.

Nesse sentido, estão sendo desenvolvidos trabalhos pela UNESCO especialmente nos chamados "países periféricos" da Europa Oriental, com o objetivo de afirmar que o desenvolvimento não caminha sem uma especial ênfase ao desenvolvimento da cultura local, ou seja, é preciso reforçar a consciência dessas culturas em relação ao seu desenvolvimento.

Todavia o desenvolvimento econômico teve seu sentido ampliado para desenvolvimento econômico e sustentável, pois de acordo com o relatório da UNESCO (1996), as pessoas perceberam que a coesão econômica por si só não poderia proporcionar um programa para a dignidade humana e ao bem estar.

O Programa das Nações Unidas para o Desenvolvimento (PNDU) que utiliza dados da UNESCO vem buscando outros critérios que levaram à elaboração do conceito de desenvolvimento humano:

\footnotetext{
'Um processo amplo de escolhas do povo' - que mede desenvolvimento em uma ampla variedade de capacidades, que vão desde política, econômica e social, liberdade ao indivíduo possibilidades de serem saudáveis, educadas, produtiva, criativa e desfrutar de auto-respeito e dos direitos humanos.

A Cultura estava implícita nesta noção, e veio a ser evocado distinguir grupos como a Comissão Brandt, a Comissão do Sul, a Comissão Mundial sobre Meio Ambiente e Desenvolvimento e da Comissão sobre Governança Global. Edifício cultural insights sobre a mais ampla estratégias de desenvolvimento, bem como tornar mais eficaz a prática agenda, teve de ser a próxima etapa de repensar o desenvolvimento (ORGANIZAÇÃO DAS NAÇÕES UNIDAS PARA A EDUCAÇÃO, A CIÊNCIA E A CULTURA, 1996).
} 
Na União Européia o Gabinete de Planejamento, Estratégia, Avaliação e Relações Internacionais (GPEARI), é o representante do Ministério da Cultura junto à UNESCO, participando na Conferência Geral, reunião bienal onde se definem as orientações, prioridades e iniciativas que incluem a adoção de atos de caráter normativo, chamado de Convenções, com relevância mundial.

Para Vecchiatti (2004) a perspectiva do desenvolvimento sustentável pressupõe uma atitude psicológica essencialmente de visão futura, sendo difícil a previsão das vertentes implicadas na evolução econômica cultural. À medida que a população se conscientiza da existência da cultura como fonte geradora de recursos financeiros, vai se formando um quadro de responsabilidade e desenvolvimento do setor.

Para se atingir tal estágio, o desenvolvimento da cultural deve partir do reconhecimento dos cenários nos quais a sociedade interage na construção de espaços, reconhecendo valores a respeito da vida em comunidade. A partir de então, incentivar o desenvolvimento da cultura, não apenas como produto consumível com viabilidade de mercado, mas sim como um bem capaz de promover o desenvolvimento econômico e de integração entre regiões e nações. Compreendendo a cultura como um processo de criação de significados que oferecem sentido ao modo de vida das comunidades humanas.

Vecchiatti (2004) assegura que pensar na cultura como fator de desenvolvimento significa valorizar identidades individuais e coletivas, promovendo a coesão em comunidades levando em consideração que as características da cultura podem ser um fator de crescimento em determinada região.

Respeitando e valorizando as características que a cultura apresenta que são a singularidade, o simbólico e o intangível, que compõe os pilares da economia criativa, onde diferentes agentes são envolvidos, com tarefas $\mathrm{e}$ formatos variados $\mathrm{e}$, conseqüentemente, resultados distintos. Porém com forte potencial desenvolvimentista.

Seguindo o raciocínio, são desenvolvidos subtópicos com o intuito de detalhamento do assunto. No primeiro, a identidade cultural, é feito uma breve definição de como é definida e percebida a cultura e sua relação com o ser humano. Nos subtópicos seguintes é dissertado sobre as características econômicas intrínsecas na cultura, a relação envolve cultural e econômica, finalizando esse tópico com as relações internacionais e a interconexão cultural existente.

\section{IDENTIDADE CULTURAL}

A cultura pode ser definida de várias maneiras. Sendo que o sentido etimológico deriva do cultivo da terra, em uma abordagem antropológica a palavra cultura, compreende conhecimento, crença, língua, valores morais, costumes, atitudes, artes e leis de um povo. Em sentido mais restrito da palavra, pode ser o conjunto de manifestações artísticas de uma nação, costumes e hábitos sociais e comportamentais ou ainda a linguagem ou até mesmo a civilização de determinadas regiões (REIS, 2007).

Em uma percepção individual ou coletiva $\mathrm{O}$ conceito amplo de cultura pode ser definido como as características humanas que se criam ou aprimoram por meio da transmissão pela 
comunicação entre as pessoas, o modo que indivíduos ou comunidades respondem às suas próprias necessidades e desejos simbólicos. Ou seja, o conjunto de aspectos da coletividade que estão relacionados a produção e transmissão do conhecimento, criação intelectual e artística.

De acordo com Martins (2008) o ser humano é dotado de capacidade de pensar a realidade que o circunda e de construir significados para sua natureza, que vão além daqueles percebidos imediatamente e é a essa construção simbólica que se dá o nome de cultura.

Portanto o sentido amplo de cultura engloba desde a língua que falamos, as idéias de um grupo, as crenças, os costumes, os códigos, as instituições, a arte, a religião, toda as atividades humana. Partindo desse ponto de vista, podemos dizer que tudo o que faz parte do mundo humano é cultura.

\section{CARACTERÍSTICA E RELAÇÃO ENTRE ECONOMIA E CULTURA}

A humanidade vem encontrando diversos problemas típicos da sociedade moderna, dentre os quais a dificuldade em compatibilizar o crescimento econômico e o desenvolvimento sustentável. Para que ocorra essa compatibilidade se faz necessário uma análise das dimensões sociais, econômicas e culturais, analisando as variáveis que compõe todo esse grande desafio, que é atender as demandas das necessidades tangíveis e intangíveis de toda uma sociedade globalizada de maneira eficiente e eficaz.

Nesse sentido pode-se constatar a necessidade de implementação de políticas públicas voltadas para o desenvolvimento sustentável em dimensão global, por meio de medidas não degradantes, porém sustentáveis e racionais do uso dos recursos naturais, estimulando o crescimento econômico proveniente de fontes de recursos não esgotáveis, tais como a cultura.

O conceito de economia da cultura rompe com a noção de que o tempo consumido livremente não gera renda, mas sim, reúne todas as atividades econômicas que integram relações com atividades culturais, seja ela como fornecedora de bens e serviços, inclusive os relacionados ao comércio internacional, ou como produto final que viabiliza seu consumo.

De acordo com Leitão (2007) a expressão economia da cultura identifica o conjunto de atividades econômicas relacionadas à cultura, incluindo a criação e o fazer cultural, o conjunto das atividades culturais que têm algum impacto econômico, ou seja, qualquer prática direta ou indiretamente cultural que gere valor econômico, além do valor cultural.

A economia é, portanto, uma das dimensões da cultura. E a economia da cultura constitui um campo da economia. Por tratar de atividades geradoras de valor econômico o setor cultural e criativo são as que constituem o campo da economia da cultura e influenciam outros setores, como os de ciência e tecnologia e de eletro-eletrônicos.

Na economia da cultura, a cultura, na vertente econômica e social, manifesta-se como:

- O elemento que faz a promoção do país além de suas fronteiras; 
- Um produto que melhor define a singularidade de um povo;

- Elemento que melhor concretiza e realiza a unidade da Nação.

Segundo Silva (2007), na história da cultura é reconhecida a tradição de apoio às artes e à cultura por parte de políticos importantes, como príncipes ou governantes, ou mesmo empresários, financistas ou amadores esclarecidos. Porém a produção, a circulação e o consumo de bens e serviços culturais começaram a ser percebidos como um segmento relevante na economia das nações apenas no pós-guerra.

Para Matoso (2006).

A relação entre cultura e economia é desde o Séc. 18 uma afinidade à qual os grandes economistas sempre deram atenção. Adam Smith e David Ricardo chegaram à conclusão que a arte produz externalidades positivas, isto é, que arte - e de um modo geral a cultura - produz efeitos benéficos na economia de outras atividades.

Na teoria das vantagens comparativas de David Ricardo (apud SINGER, 2002), cada país tem determinada vantagem na produção de um bem e não de outro, sendo que essas vantagens podem ser naturais ou adquiridas. Dentre as vantagens adquiridas estão a produção industrial e os serviços (SINGER, 2002), estando a economia da cultura dentro desse contexto.

De acordo com Melo (2008), o estudo sobre economia da cultura teve inicio em 1960, nos Estados Unidos da América, e na década de 70 a Organização das Nações Unidas para a Educação, a Ciência e a Cultura (Unesco) convocou seus membros a produzirem estatísticas referentes a cultura. Porém, foi a partir da segunda metade da Década de 1980 que se iniciou a discussão mais aprofundada a respeito da dimensão econômica da cultura, com a criação da Association for Cultural Economics International (ACEI) conforme afirma Bertini (2008).

Depois de permanecer fora dos cálculos econômicos, eis que a economia do setor cultural é vista como fator de produção e desenvolvimento, aparecendo em debates, tanto nacionais como internacionais, como objeto de negociações na Organização Mundial do Comércio (OMC), como também pelo reconhecimento da diversidade cultural, cujo ator principal é a UNESCO (INTERNATIONAL CENTRE FOR TRADE AND SUSTAINABLE DEVELOPMENT 2007).

A França foi um dos primeiros países a tomar a iniciativa dos estudos referentes ao setor da economia que envolve a cultura (TOLILA, 2007).

A dimensão econômica do setor cultural na atualidade está sendo analisada, a partir do cruzamento de dados coletados em pesquisas realizadas pelo Instituto Brasileiro de Geografia e Estatística (IBGE) em censo demográfico, amostras de domicílios, economia informal, orçamentos familiares, padrões de vida, pesquisa mensal de emprego, informações básicas municipais, cadastro central de empresas, pesquisas anuais de serviços, indústria-empresa e indústria-produto (MELO, 2008).

Fortalecendo a teoria desenvolvimentista da economia, o Relatório sobre a Situação da População Mundial 2008 das Nações Unidas, lembra que a construção cultural influencia a maneira como as pessoas vivem e, portanto, afeta o modo de agir e de pensar da sociedade, mas não faz com que todos ajam da mesma forma. A publicação destaca ainda, que o 
desenvolvimento cultural deve ser um direito assim como o desenvolvimento econômico e social (LABOISSIÈRE, 2008).

Entretanto, apesar da nítida contribuição para o desenvolvimento econômico aliado a sustentabilidade, por se tratar de uma atividade econômica independente de recursos naturais esgotáveis, é notada que é um campo deficitário no que tange a políticas publicas direcionadas ao setor, ignorando a força propulsora do setor como gerador de emprego e renda e tendem a ver a cultura apenas como dispêndio de tempo sem retorno econômico.

No Brasil o Ministério da Cultura vem implementando ações buscando parcerias com órgãos financeiros e governamentais, visando o desenvolvimento da economia da cultura dentro e fora do país.

Em junho de 2006, foi aprovado o Programa de Desenvolvimento da Economia da Cultura (PRODEC), no Plano Plurianual do Governo Federal, com isso, os indicadores de estatísticas, diagnósticos, capacitação, promoção de negócios, divulgação de produtos e serviços culturais passaram a ter orçamento próprio a partir de 2007 (BRASIL CULTURA, 2008).

O setor cultural demanda cada vez mais alocações de recursos de maneira quantificada no que diz respeito à expansão econômica em geral. Para Tolila (2007), a economia do setor cultural (entenda-se por isso os resultados dos estudos econômicos, a capacidade de produzir sínteses úteis e comparações confiáveis) ainda se caracteriza por uma grande dispersão, escassez e ausência de dados atualizados e uma grande dificuldade de amarrar os níveis da microeconomia e da macroeconomia.

A diversidade cultura se manifesta na originalidade e na pluralidade de identidades que caracterizam grupos e as sociedades que compõe a humanidade mundial. É fonte de intercâmbios, de inovação e de criatividade. Constitui o patrimônio comum da humanidade, devendo ser reconhecido e consolidado em beneficio de gerações futura.

De acordo com Porta (2008), a partir da década de 1970 com o inicio do interesse pelo setor, é que a Economia da Cultura começa a despertar interesse em pesquisadores de algumas universidades.

No período de 1990, o tema ganha espaço nos órgãos internacionais de cooperação, começando a ser entendida como um vetor de desenvolvimento. Progressivamente órgãos como Banco Interamericano do Desenvolvimento (BID), Programa das Nações Unidas para o Desenvolvimento (PNUD), Organização dos Estados Americanos (OEA), Organização das Nações Unidas para a Educação, a Ciência e a Cultura (UNESCO) passam a incluir questões relacionadas à Economia da Cultura em seu escopo de ação.

As atividades culturais de um país em outro favorecem o fortalecimento de um clima de confiança nas qualificações desse país. Em outras palavras: as características de confiabilidade de um determinado produto comercial se vêem grandemente fortalecidas se inseridas no contexto cultural a que pertencem. Nessa concepção, o Brasil por vezes vende apenas produtos, ao passo que a França, por exemplo, exporta charme (RIBEIRO, 2008).

Diante da necessidade de proteger as diversidades culturais em ritmo acelerado de internacionalização, entrou em vigor a Convenção sobre a Proteção da Diversidade das. 
Expressões culturais em março de 2007 (ORGANIZAÇÃO DAS NAÇÕES UNIDAS PARA A EDUCAÇÃO, A CIÊNCIA E A CULTURA, 2008).

A titulo de curiosidade citamos a decrescente diversidade de idiomas é um exemplo interessante: existem mais de 6 mil idiomas vivos no mundo, mas aqueles utilizados no comércio e em novas tecnologias são cada vez mais dominantes. Por outro lado, estima-se que um idioma desaparece a cada duas semanas. A previsão é que $90 \%$ deles estarão extintos dentro dos próximos 100 anos.

\section{RELAÇÕES ECONÔMICAS E CULTURAIS}

Dentro da dinâmica das relações econômicas o Brasil tem feito amplo uso de acordos, em suas negociações bilaterais de natureza política, econômica, comercial, cultural, científica e técnica. Um dos mais importantes tratados multilaterais é o Acordo Geral de Tarifas e comércio General Agreement on Tariffs and Trade (GATT). Assinado em 1947, com a função de promover a liberalização comercial e de combater práticas protecionistas, como também de regular as relações internacionais por meio de regras estabelecidas pelos países signatários.

Fiori (2005) afirma que a institucionalização do GATT como um foro de negociações comerciais resultou em uma primeira rodada de negociações ainda em 1947 sendo as grandes potências a definirem as regras do comércio internacional para produtos manufaturados.

Naquele momento foi criada a cláusula central do Acordo, a chamada cláusula de nação mais favorecida, que determina toda e qualquer concessão feita por uma nação a um parceiro comercial deve ser estendida a todos os países signatários do GATT.

Com a Rodada Uruguai, a mais ampla e complexa de todas as rodadas de negociações comerciais realizadas de 1986 à 1993, ainda sob os cuidados do GATT, o sistema multilateral de comércio iniciou uma nova fase, com maiores compromissos e obrigações para os seus participantes. As novas regras que norteiam o comércio internacional passam a estar sob a guarda da Organização Mundial do Comércio (OMC), a quem cabe a administração do sistema multilateral de comércio desde janeiro de 1995. Os acordos sob sua responsabilidade especificam os parâmetros básicos que seus membros devem observar ao definir suas práticas comerciais, de modo a garantir acesso aos mercados, condições justas de competição e previsibilidade no âmbito do comércio internacional. (RÊGO, 2009).

Dentro desse contexto de negociações comerciais, durante a Rodada de Doha, iniciou-se a discussão da comercialização indiscriminada da cultura, por sua relevante importância tanto em âmbito desenvolvimentista, mas também pela peculiar característica de formação do individuo.

As negociações de comércio multilaterais em Doha lançada em 2001, que deveriam ter sido concluídas em 2005, porém se alongou até 2008. Houve debates sobre os serviços culturais e outros serviços criativos sob o "Acordo Geral sobre o Comércio de Serviços" (GATS). Um grupo de países argumenta que os serviços culturais.

Poucos países se comprometeram com os serviços culturais, na maioria os países com economia em desenvolvimento. 
As indústrias criativas são se caracterizam pela alta dependência de proteção e execução dos direitos de propriedade intelectual. A entrada em vigor das provisões do Acordo sobre os Aspectos dos Direitos da Propriedade Intelectual Relacionados ao Comércio (Acordo TRIPs) poderá aumentar significativamente o nível de proteção e de execução dos direitos de propriedade intelectual nos países em desenvolvimento (REIS, 2008).

Lima (2003) defende que o comércio cultural não pode ser apenas o resultado de cálculos para obter vantagens comparativas que predominariam, seguindo um frio racionalismo econômico e que um enfoque meramente mercadológico, o do livre-comércio global, não seja o único parâmetro no tocante à questão da circulação de bens e serviços culturais.

Porém há que se destacar a sua evidente importância para toda nação em termos econômicos. O comércio global em de bens culturais, citando Reis (2008)

[.....] baseados em declarações alfandegárias, o comércio mundial de bens culturais praticamente dobrou, de US\$39,3 bilhões, em 1994, para US\$59,2 bilhões, em 2002. Entretanto, os benefícios desse comércio em 2002 eram fortemente concentrados em poucos países, em especial Reino Unido (exportações de 8,5 bilhões de dólares), Estados Unidos (US\$7,6 bilhões) e China (US\$5,2 bilhões). E essa tendência deve se perpetuar. Nos dizeres de Xiong, "como acesso da China à Organização Mundial do Comércio, as trocas culturais estão explodindo e mais e mais produtos e serviços criativos e atraentes serão exportados". Por outro lado, América Latina e Caribe, somados, não passaram de $3 \%$ do mercado, enquanto Oceania e África representaram $1 \%$ das exportações globais.

A Economia da Cultura é hoje o setor de maior dinamismo na economia mundial, tem registrado crescimento de $6,3 \%$ ao ano, enquanto o conjunto da economia cresce a 5,7\%. A Economia da Cultura integra o segmento de serviços e lazer, cuja projeção de crescimento é superior à de qualquer outro, estima-se que cresça $10 \%$ ao ano na próxima década. Esse potencial de crescimento é bastante elástico, pois o setor depende pouco de recursos esgotáveis, já que seu insumo básico é a criação artística ou intelectual e a inovação (PORTA, 2008).

Aqui no Brasil, a discussão sobre a Economia Criativa teve início em 2005, com a realização do Fórum Internacional de Indústrias Criativas, em Salvador. Em novembro de 2006, o tema ganhou mais ênfase com a inclusão de um módulo voltado à economia criativa, no Fórum Cultural Mundial do Rio de Janeiro (BRAGA, 2007).

O Banco Mundial estima que a Economia da Cultura responda por $7 \%$ do Produto Interno Bruto (PIB) mundial em 2003. Nos Estados Unidos da América a cultura é responsável por $7,7 \%$ do PIB, por $4 \%$ da força de trabalho e os produtos culturais são o principal item de exportação do país em 2001. Na Inglaterra, corresponde a 8,2\% do PIB no ano de 2004, empregando 6,4\% da força de trabalho e cresce 8\% ao ano desde 1997 (PORTA, 2008).

De acordo com a INTERNATIONAL CENTRE FOR TRADE AND SUSTAINABLE DEVELOPMENT - ICTSD (2007) desde o início da década de 80, o comércio internacional de bens culturais aumentou quase seis vezes: subiu de US\$ 9,5 bilhões em 1980 para US\$ 60 bilhões em 2002. De acordo com o Banco Mundial, as indústrias culturais e criativas são responsáveis por mais de $7 \%$ do PIB mundial, conforme já citado anteriormente, o que corresponde a um valor comercial global de US\$ 1,3 trilhão. São poucos, entretanto, os países que detêm as grandes exportações de produtos culturais: a Europa lidera, com 51,8\%, seguida da Ásia $(20,6 \%)$ e da América do Norte $(16,9 \%)$. Os países ricos também dominam as 
importações desses produtos - mais de $90 \%$ do total mundial importado - com destaque para os Estados Unidos da América (EUA), Reino Unido e Alemanha. América Latina e África foram responsáveis por $3 \%$ e $1 \%$, respectivamente, do comércio mundial de bens culturais em 2002.

Ainda de acordo com a INTERNATIONAL CENTRE FOR TRADE AND SUSTAINABLE DEVELOPMENT (2007) as indústrias culturais substituem progressivamente as formas tradicionais de criação e disseminação do conhecimento, o que gera mudanças nas práticas culturais.

\section{RELAÇÕES INTERNACIONAIS E A INTERCONEXÃO CULTURAL}

As relações internacionais vêm se caracterizando por importantes eventos e processos, que de forma crescente estão afetando as relações de poder no que diz respeito tanto ao cenário internacional, quanto dentro dos próprios países.

Segundo Latoeira (2007) o grau de exigência da população vem se alterando, cada vez mais, a migração de pessoas que vem ocorrendo em busca de novas oportunidades de emprego, de formação, diversidade cultural, troca de experiências culturais, novas oportunidades de negócio e possibilidade para expressar a sua própria identidade. Esse movimento migratório tem contribuído com o surgimento de uma população mais aberta e acolhedora o que será uma mais valia para atrair indivíduos com diferentes modos de vida, nomeadamente os que desenvolvam atividades que integram uma forte componente criativa na geração de bens e serviços.

Para se compreender a política mundial contemporânea é necessário pesquisar não apenas as estratégias de Estado e das organizações governamentais internacionais, mas também as organizações não governamentais internacionais, a sociedade de modo geral, inclusive comunidades religiosas, étnicas, os mercados internacionais, as comunidades científicas, como também os blocos econômicos.

Compreender as dinâmicas internacionais significa entender os fatores que atuam nas atividades econômicas, políticas e sociais que envolvem o Brasil no contexto internacional. Ayerbe (2003) afirma que:

No mundo flui uma importante e promissora corrente intelectual concentrada na cultura e nas mudanças culturais, que têm relevância tanto para os países pobres como para as minorias pobres dos países ricos... Oferece uma visão importante sobre a razão pela qual a alguns países e grupos étnicos e religiosos se saíram melhor do que a outros, não só em termos econômicos, como também com respeito à consolidação das instituições democráticas e a justiça social.

As relações internacionais que envolvem a economia da cultura são caracterizadas pela particularidade de bens e serviços culturais não serem tangíveis, mas sim, ir bem além da dimensão puramente econômica, por ser expressão do valor cultural que extrapola as regras convencionais praticadas pelos mercados.

De acordo com Ribeiro (2008) não existe cooperação comercial ou técnica sem que se considere a cultura do país ao qual ela se destina. 
"A cultura é um pano de fundo contra o qual as relações internacionais deveriam transitar em benefício comum” (RIBEIRO, 2008).

As políticas culturais estão baseadas nos direitos e na idéia de universalidade do acesso aos bens culturais. A democratização e o acesso à cultura são valores de ampla aceitação entre as diferentes sociedades.

O peso da produção cultural nos processos de desenvolvimento e integração social perpassa pela dimensão da vida em sociedade e se relaciona com processos de sociabilidade e de sua própria reprodução, ou seja, com um olhar mais criterioso, percebe-se que está relacionada aos direitos e à cidadania de um povo.

Geralmente quando se refere à cultura, esta é lembrada como a vinculação entre cultura e arte, até por que a arte representa uma das maneiras mais ricas de expressão da cultura. Porém devese compreender que ela é também responsável pelo que enriquece as relações econômicas e culturais internacionais (RIBEIRO, 2008).

A cultura pode ser caracterizada como um bem transnacional, por apresentar meios de aproximação entre os povos, capaz de facilitar as negociações entre diferentes países, proporcionando a integração regional, a exemplo do que vem ocorrendo em eventos, o ano do Brasil na França que aconteceu em 2005 e o ano da França no Brasil que está acontecendo em 2009 é exemplo claro da presença da cultura nas relações internacionais.

Como parte das relações bilaterais entre os dois países, França e Brasil haverá uma maior cooperação em diversas áreas do conhecimento, não apenas culturais, como também, da economia e da tecnologia, e ampliação das oportunidades de intercâmbio entre os dois países.

De acordo com o Consulado Geral da França em São Paulo (2009) o ano do Brasil na França teve resultados surpreendentes, o evento mobilizou mais de 15 milhões de pessoas, com centenas de atrações realizadas em todo o território francês, que trouxeram impactos diretos não só para o intercâmbio cultural, mas também para as trocas comerciais entre os dois países.

Na ocasião, registrou-se aumento de três vezes no volume de negócios entre França e Brasil (quando comparado ao ano anterior, 2004), o que correspondeu a cerca de US\$ 450 milhões de produtos brasileiros importados pela França em 2005.

De acordo com dados do jornal Tribuna da Costa (2008) a França é o quarto país europeu que mais envia turistas para o Brasil, lembrando que de 2005 para 2006 o crescimento do fluxo de franceses para o Brasil já chegou a 4,6\%. Esse aumento se deve a promoção do ano do Brasil na França.

\section{INDICADORES ECONÔMICOS DO CENARIO CULTURAL DO BRASIL}

O conceito, de economia da cultura, surgido inicialmente em 1994, na Austrália, ganhou importância quando, em 1997, o então primeiro-ministro britânico Tony Blair, preocupado com as perspectivas econômicas do país no cenário competitivo mundial, diante de um quadro de decadência manufatureira, identificou treze setores que poderiam reerguer a economia 
nacional. A eles deu o nome de "indústrias criativas" (SECRETARIA DE DESENVOLVIMENTO/SP, 2007).

O que esses setores têm em comum, segundo o conceito britânico, é a possibilidade de gerar direitos de propriedade intelectual, em especial os autorais. Nesse leque entram não só as indústrias culturais e o artesanato, como também moda, design, arquitetura e setores cujo componente cultural apresenta diferentes nuances, como da propaganda e do software.

No Brasil, a discussão sobre Economia Criativa teve início em abril de 2005, com o Fórum Internacional de Indústrias Criativas, em Salvador. Em novembro de 2006 a questão alçou novo vôo com a inclusão de um módulo especificamente voltado à economia criativa, no âmbito do Fórum Cultural Mundial do Rio de Janeiro (SÃO PAULO, SECRETARIA DE DESENVOLVIMENTO, 2007).

Para Leitão (2007) a cultura é um bem altamente diversificado e capaz de estabelecer um ambiente favorável às políticas desenvolvimentistas, ou seja, Cultura é mercadoria. Mas um tipo de mercadoria distinta, que apresenta duplo valor: econômico e cultural.

Mensurar economicamente a cultura não é só possível, mas necessário, pois por meio de análises econômicas podem ser entendidos os fenômenos culturais. E reforçar uma percepção positiva das atividades culturais, ao conferir a elas valor mensurável.

O comércio mundial de bens e serviços culturais movimentou US\$ 1,3 trilhão em 2005. Este dado afirma a importância econômica da cultura, além da "cultural" (LEITÃO, 2007).

No Brasil, o principal registro relativo ao interesse pela economia da cultura se deu a partir do momento em que a Fundação João Pinheiro (MG), por solicitação do Ministro da Cultura, fez uma breve analise do setor, com o objetivo de verificar a participação do setor cultural no PIB Brasileiro (BERTINI, 2008).

A seguir são apresentados subtópicos que possibilitam ao leitor uma visão do cenário em que estão as relações econômicas com a economia, apresentando alguns dos aspectos e possibilidades mostrados com dados fornecidos pelo Instituto Brasileiro de Geografia e Estatística (IBGE) do setor de produção cultural, em outro sub-tópico é colocada a importância do setor cultural no que tange a contribuição econômica, inclusive para o PIB brasileiro e sua crescente participação no desenvolvimento do país.

\section{POSSIBILIDADES E LIMITES DOS INDICADORES CULTURAIS}

As atividades culturais na contemporaneidade estão cada vez mais demonstrando sua importância dentro do quesito crescimento, o que provoca impacto direto nas relações economias em geral no que tange a geração de emprego, renda, produção e demanda, proporcionando aumento de arrecadação de impostos e contribuindo para o desempenho do Produto Interno Bruto.

É notado o crescente interesse pelo tema, por meio do número significativo de países e organizações internacionais que vêm dedicando cada vez mais atenção à produção de 
conhecimento sobre as especificidades e potencialidades das atividades direta ou indiretamente relacionadas à cultura, dentro de um contexto de globalização e da evolução crescente e rápida dos modos de produção, distribuição, consumo e de mudanças dos produtos culturais. Porém, ainda é identificada a dispersão das informações e precariedade de dados estatísticos sobre as atividades de produção e serviços de bens culturais o que dificulta a correlação entre os níveis da microeconomia e da macroeconomia.

O conceito de desenvolvimento sustentável surgiu na década de 80 e consagrado em 1987 pela Comissão Mundial sobre o Meio Ambiente - CMMA das Nações Unidas, conhecida como Comissão Brundtland (VECCHITTI, 2004), que produziu um relatório:

[....] um processo de transformação no qual a exploração dos recursos, a direção dos investimentos, a orientação do desenvolvimento tecnológico e a mudança institucional se harmonizam e reforçam o potencial presente e futuro [...] é aquele que atende às necessidades do presente sem comprometer a possibilidade de as gerações futuras atenderem às suas próprias necessidades (INSTITUTO BRASILEIRO DE GEOGRAFIA E ESTATÍSTICA, 2002).

Apesar de não haver informações totalmente sistematizadas sobre o seu impacto na economia brasileira, a Cultura é responsável aproximadamente por 4\% do PIB e é reconhecida como um eixo estratégico de desenvolvimento (PORTA, 2008).

O Ministério da Cultura do Brasil vem trabalhando para construir uma agenda de desenvolvimento da Economia da Cultura e já iniciou uma série de ações fundamentais com parceiros.

Em 2006, O Programa de Desenvolvimento da Economia da Cultura (Prodec) foi inserido no Plano Plurianual do Governo Federal. Com isso, a construção de indicadores e estatísticas, diagnósticos, capacitação, promoção de negócios, divulgação de produtos e serviços culturais passam a ter orçamento próprio do Governo Federal.

O IBGE divulgou, no final de 2006, o Sistema de Informações e Indicadores Culturais (SIIG), primeira sistematização das informações sobre a Economia da Cultura, realizada com base em pesquisas de 2003. Este documento lança as primeiras luzes sobre este universo até então desconhecido da economia brasileira.

Observa-se, entretanto, que em países com rica diversidade regional, inclusive o Brasil, ainda há falta de informação sistematizada (qualitativa e quantitativa) oficial sobre as relações entre o mundo da cultura e o mundo da economia.

Neste estudo, a análise econômica da cultura foi realizada por meio da mensuração dos produtos (bens e serviços) ofertados e consumidos. Convém ressaltar que, mesmo partindo de um princípio conceitual e metodológico simples (estudo da oferta e demanda de produtos associados à cultura), houve enorme dificuldade para mensurar a importância econômica da cultura no Brasil, em virtude da insuficiência de dados estatísticos sobre as atividades de produção de bens culturais no País (INSTITUTO BRASILEIRO DE GEOGRAFIA E ESTATÍSTICA, 2006). 
Em 2003, atuavam na produção cultural brasileira, de acordo com o Cadastro Central de Empresas (CEMPRE) do IBGE, 269.074 empresas, responsáveis pela ocupação de 1.431.449 pessoas, das quais 1.007.158 eram assalariados.

O setor com maior participação foi o de Serviços, com aproximadamente 59\% das empresas e $62 \%$ do pessoal ocupado do total e do assalariado sendo na área da Cultura. As famílias brasileiras gastavam, em 2003, em média, cerca de $7 \%$ do seu orçamento em produtos culturais, quando são considerados os gastos em telefonia, representando a quarta maior despesa, superada apenas por habitação, alimentação e transporte (INSTITUTO BRASILEIRO DE GEOGRAFIA E ESTATÍSTICA, 2006).

Portanto, é notado que a contribuição economia dos serviços, que envolvem os negócios da cadeia de produção Cultural no Brasil, vem se despontando como eixo promissor para o desenvolvimento de estratégias, parcerias e ações.

A ênfase na cultura como fator de sustentabilidade ainda é muito recente. $O$ seu desenvolvimento é um importante fator, pois não se restringe a um segmento específico, mas permeia diversas ações da sociedade. É um fenômeno que ocorre pelo fator criatividade, inerente a capacidade humana, no desenvolvimento cultural e avanço tecnológico. No atual contexto econômico, a sociedade vem se assegurando no capital cognitivo como forma de crescimento (BERTINI, 2008).

\section{IMPORTÂNCIA DO SETOR}

Segundo a Pesquisa Nacional por Amostra de Domicílios - PNAD, em 2006, dos 89,3 milhões de trabalhadores com 10 anos ou mais de idade no Brasil, 4,2 milhões estavam vinculados a ocupações ou atividades relacionadas à cultura. Os dados da PNAD mostram, que de 2005 para 2006, a população ocupada no Brasil cresceu 2,4\%, enquanto que nas ocupações ou atividades relacionadas à cultura, verificou-se um crescimento maior $(5,4 \%)$. Do total de pessoas ocupadas no Brasil, no ano de 2006, 4,8\% exerciam ocupações relacionadas às atividades culturais. Em 2005, representava 4,6\% do total de ocupados e, em 2004, 4,5\%. A Região Sudeste apresentou a maior proporção de ocupados nessas atividades em 2006 (5,7\%), seguida pela Região Sul (4,8\%). Nas Regiões Norte, Nordeste e Centro-Oeste o setor cultural representava 3,2\%, 4,0\% e 3,8\% da população ocupada, respectivamente (INSTITUTO BRASILEIRO DE GEOGRAFIA E ESTATÍSTICA, 2007).

Considerando-se o grande potencial do setor, o Ministério da Cultura e o Governo do Distrito Federal, firmarão acordo de cooperação para implantação conjunta das ações do Programa Mais Cultura no Distrito Federal no dia $1^{\circ}$ de junho de 2009. Na ocasião o ministro Juca Ferreira destacou a importância do acordo para o desenvolvimento do setor, pois a Cultura é um direito básico da cidadania e importante instrumento para a geração de emprego e renda. $\mathrm{O}$ Ministro salientou ainda que apesar dos dados apresentados do setor cultural, cerca de $7 \%$ do Produto Interno Bruto (PIB) nacional e gera 5\% dos empregos formais do país, mais da metade dos trabalhadores da cultura estão na informalidade (MINISTÉRIO DA CULTURA, 2009).

No entanto, mais da metade dos trabalhadores da cultura estão na informalidade. Então a cultura tem forte potencial para contribuir, no mínimo, com $10 \%$ do PIB, o que não é pouco. Precisamos fomentar a cultura não somente por sua dimensão humana e simbólica, mas também por seu potencial econômico (FERREIRA, 2009). 
Conforme o ministro, o Programa Mais Cultura constitui-se no principal programa da pasta para promover o acesso da população brasileira a bens e serviços culturais.

\section{A PARTICIPAÇÃO NO BALANÇO DE TRANSAÇÕES INTERNACIONAIS}

A atividade terciária, em todo o mundo, representa $50 \%$ dos custos de produção e mais de $50 \%$ dos empregos totais. Apesar de $75 \%$ do comércio mundial de serviços estar concentrado em nações desenvolvidas, sua importância para as economias em desenvolvimento vem se mostrando cada vez significativa. Os serviços representam aproximadamente $80 \%$ do PIB nos países desenvolvidos e quase $60 \%$ do PIB brasileiro. O conteúdo de serviços na indústria manufatureira e a dependência dessa indústria em relação às atividades terciárias são crescentes (MINISTÉRIO DO DESENVOLVIMENTO, INDÚSTRIA E COMÉRCIO EXTERIOR, 2008).

No ano de 2006, o Brasil ocupou a trigésima posição no ranking dos principais exportadores e a vigésima quinta colocação entre os principais importadores mundiais. Em 2006, as exportações brasileiras de serviços foram de US\$ 17.943 bilhões contra US\$ 14,855 bilhões, no ano anterior, o que representou um crescimento de 20,8\%. Os principais mercados de destino de nossas exportações e origem de nossas importações foram os Estados Unidos e a União Européia com participação de, respectivamente, 76,6\% e 82,2\% (MINISTÉRIO DO DESENVOLVIMENTO, INDÚSTRIA E COMÉRCIO EXTERIOR, 2008).

De acordo com o Ministério do Desenvolvimento, Indústria e Comércio Exterior o ano de 2007 confirmou a forte expansão do comércio exterior de serviços do Brasil. As exportações de serviços totalizaram US\$22,5 bilhões com crescimento de $25,7 \%$ sobre o ano anterior, valor superior à expansão das exportações de bens, de $16,6 \%$, no mesmo período. As importações de serviços também cresceram, totalizando US\$34,8 bilhões, em 2007, contra US\$ 27,1 bilhões anotados no mesmo período do ano anterior. As maiores receitas foram registradas nos seguintes setores: Serviços Empresariais e Profissionais (US\$ 10,1 bilhões), Viagens Internacionais (US\$ 4,9 bilhões), Transportes (US\$ 4,0 bilhões), Serviços Financeiros (US\$ 1,1 bilhão) e Serviços Relativos ao Comércio (US\$ 956 milhões).

Ainda segundo o Ministério do Desenvolvimento, Indústria e Comércio Exterior os serviços são insumos fundamentais para qualquer economia moderna, permeiam todas as cadeias produtivas e têm papel importante na difusão de inovações e ganhos de produtividade para outros setores.

Dentro da classificação de serviços estão os bens e serviços culturais exportados pelo Brasil que apesar de apresentar déficit na soma geral dos valores, mostra que para alguns países ocupa a $1^{\mathrm{a}}$ ou $2^{\mathrm{a}}$ colocação nas exportações de serviços, conforme dados do Banco Central do Brasil referente à balança de serviços, como mostra as tabelas e gráficos a seguir. 
Tabela 1- Serviços adquiridos países baixos 2007

\section{SERVIÇOS BRASILEIROS ADQUIRIDOS PELOS PAÍSES BAIXOS POR SETOR} Janeiro/Dezembro - 2007 - PARTICIPAÇÃO \%

\begin{tabular}{|l|}
\hline 1- Serviços Culturais e Ambientais \\
\hline 2- Telecomunicações \\
\hline 3- Fabricação de Máquinas e Equipamentos \\
\hline 4- Serviços Financeiros \\
\hline 5 - Consultoria em Gestão Empresarial \\
\hline 6 - Comércio por Atacado, Exceto Veículos Automotores \\
\hline 7- Serviços de Escritório e Apoio Administrativo \\
\hline 8- Serviços Jurídicos, Contábeis e de Auditoria \\
\hline 9- Serviços de Tecnologia da Informação \\
\hline 10 - Correios e Outras Atividades de Entrega \\
\hline
\end{tabular}

Fonte: Banco Central do Brasil. 2009.

De acordo com os dados apresentados na tabela 1, é possível uma verificação da importância em termos de valor econômico, dos bens e serviços culturais dentro da pauta de exportação de serviços do Brasil, mesmos estando, estatisticamente junto com os dados de serviços ambientais, é possível ter noção dimensional da importância do setor para o crescimento econômico do Brasil, lembrando que existe um elo entre os serviços ambientais e cultura, por ser considerada a produção cultura como produção limpa sem emissão de poluentes.

Os dados referentes a exportação de serviços, especificamente no caso de exportação para os Países Baixos, a contribuição dos serviços culturais e ambientais é maior do que a soma das participações dos outros cinco componentes da tabela apresentada (comércio por atacado, serviços de escritório e apoio administrativo, serviços jurídicos, contábeis e de auditoria, serviços de tecnologia da informação, correios e outras atividades de entrega) que juntas somam 19,3\% de participação. Estando a frente de outros serviços como os de telecomunicações, de Tecnologia de Informação, o que apresenta a força da produção cultural nas exportações do ano 2007.

O ano de 2007 foi marcado por crise de crédito que afetou as Bolsas de valores no mundo, porém para o Brasil a economia teve saldo positivo.

Com recordes na geração de empregos formal e a conseqüente elevação na arrecadação do governo. A economia brasileira, até o mês de setembro de 2007 registrou um crescimento de $5,3 \%$, em comparação ao mesmo período do ano anterior, com destaque para os setores de industria $5,1 \%$ e serviços $4,7 \%$ (INSTITUTO BRASILEIRO DE GEOGRAFIA $\mathrm{E}$ ESTATÍSTICA, 2009).

Visualizando os dados é possível uma observação mais detalhada da contribuição da produção cultural na exportação de serviços. Sendo que outros produtos que compõe a exportação de serviços também carregam a contribuição do item cultura agregado ao seu valor, como por exemplo, os serviços de tecnologia da informação que por si, apresenta o componente cultural, quando observado o modo como é desenvolvido. Em termos percentuais os serviços culturais exportados para os Países Baixos ocupam uma posição de destaque, estando no ano de 2007, dentro da pauta de exportações de serviços como primeiro colocado em termos percentuais. 
O Reino Unido também vem apresentado expressiva importação de bens culturais brasileiros, a marca do dinamismo do setor está nos resultados das exportações brasileiras no ano de 2007 para aquela região, como pode ser verificado a seguir.

Tabela 2 - Serviços adquiridos pelo Reino Unido 2007

SERVIÇOS BRASILEIROS ADQUIRIDOS PELO REINO UNIDO POR SETOR Janeiro/Dezembro 2007 Participação \%

\begin{tabular}{|l|r|}
\hline 1 - Comércio por Atacado, Exceto Veículos Automotores & 15,6 \\
\hline 2 - Serviços Culturais e Ambientais & 10,9 \\
\hline 3- Manut. Reparação e Instalação de Máquinas & 10,2 \\
\hline 4 - Serviços de Escritório e Apoio Administrativo & 7,3 \\
\hline 5 - Serv. Aux. Financeiros, Seguros e Previdência Compl. e Planos de Saúde & 7 \\
\hline 6 - Serviços de Tecnologia da Informação & 6,8 \\
\hline 7 - Serviços Financeiros & 6,2 \\
\hline 8 - Serviços Jurídicos, Contábeis e de Auditoria & 5,4 \\
\hline 9 - Obras de Infra-estrutura & 5,1 \\
\hline 10 - Armazenamento e Serv. Auxiliares de Transportes & 3,6 \\
\hline
\end{tabular}

Fonte: Banco Central do Brasil. 2009.

Os dados presentes na tabela 2 colocam os serviços culturais juntamente com os ambientais em posição de destaque nas exportações de serviços do Brasil para o Reino Unido, provando que é um setor importante dentro das exportações brasileiras, estando a frente dos serviços de escritórios e apoio administrativos, ficando atrás dos serviços de comércio por atacado.

Analisando os dados, é possível verificar uma forte presença de bens e produtos culturais brasileiros dentro do Reino Unido. Levando-se em consideração que os Países que formam o Reino Unido Inglaterra, Gales, Escócia e Irlanda do Norte, são grandes produtores de serviços culturais como também exportadores, atribuindo grande importância ao produto brasileiro.

$\mathrm{O}$ valor em percentual, apresentado é relevante em se tratando de exportação de um produto considerado como bem intangível de difícil mensuração.

Os serviços culturais e ambientais exportados pelo Brasil, especificamente ao Reino Unido, representa fator importante dentro das exportações de serviços Brasileiros. Considerando-se a forte produção de bens e serviços pelos países do Reino Unido, por se tratar de nações desenvolvidas e que o setor cultural apresenta relevância econômica

O Reino Unido é grande produtor de bens culturais, o que confere ainda maior importância ao volume exportado pelo Brasil.

Porém o país que mais importou bens culturais e ambientais do Brasil em 2007, foi a França.

Observando os dados, pode-se verificar que dentro da pauta de serviços brasileiros adquiridos pela França, o item serviços culturais e ambientais, é responsável pela alta da balança de serviços brasileira, contribuindo para diminuir o da Balança comercial brasileira.

Entretanto, mesmo com a forte presença da cultura nas transações na balança de serviços do Brasil, entre os países apresentados, o saldo entre as Despesas da conta de serviços e a Receita de serviços, ainda é deficitário conforme dados apresentados a seguir. 


\section{DESPESAS DA CONTA DE SERVIÇOS-2007 Part \%}

-1-Transporte

- Aluguel de Equipamentos

घ5-Serviços Governamentais

$\square 7$-Royalties e Licenças

9-Serv. Relativos ao Comércio

$\square 11$ - Serv. Pessoais, Culturais e Recreação

$\square$ 13-Construção

Gráfico 1 - Despesas da Conta de Serviços 2007

Fonte: Banco Central do Brasil. 2009

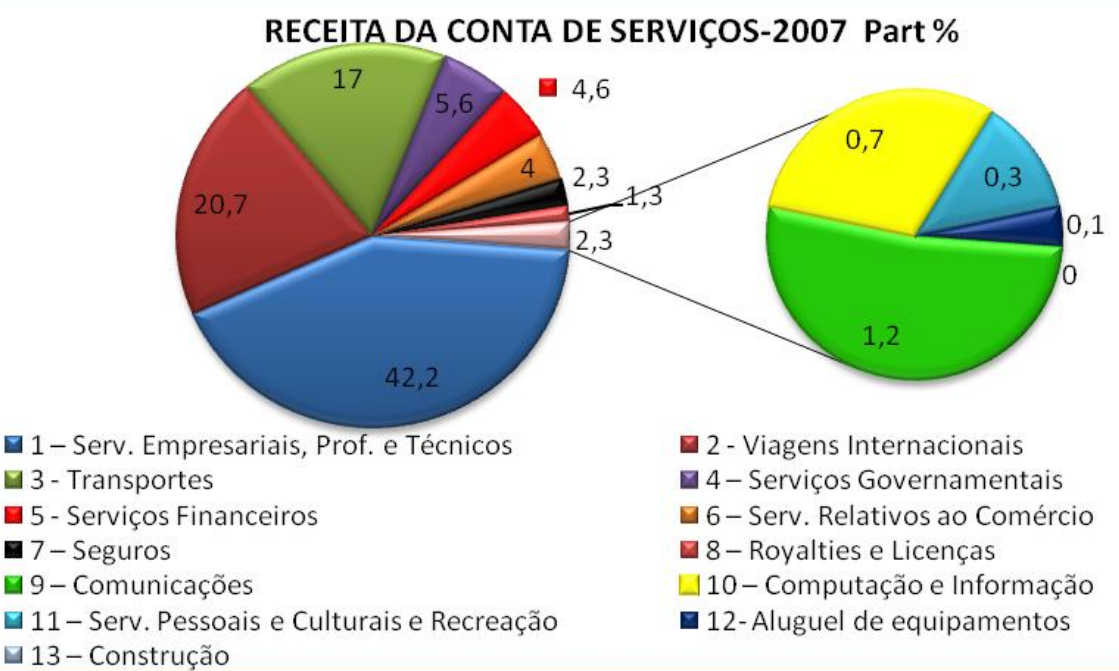

Gráfico 2 - Receita da Conta de Serviços 2007

Fonte: Banco Central do Brasil. 2009.

Comparando-se os dados dos gráficos 1 (despesas de serviços) e 2 (receitas de serviços), podemos constatar o défict apresentado pelos dados na balança de serviços.

O Brasil, apesar do grande potencial na produção de bens e serviços, vem importando mais do que exportando.

Os dados fornecidos pelo Banco Central do Brasil relativos a Receita da Conta de Serviços e Despesas da Conta de Serviços, de 2007, é possível visualizar um panorama deficitário no que tange ao setor de serviços em geral, no Brasil.

Em termos de percentuais, as despesas da conta de serviços em 2007, apresenta os serviços culturais, juntamente com os serviços pessoais e recreativos, com uma pequena participação no total das despesas. Verifica-se que os maiores volumes importados foram 
de serviços de transporte e aluguel de equipamento, o que evidencia que o brasil tem importado menos produtos culturais, esse panorama geral das despesas das contas de 2007, mostra que o sertor da cultura, que aparece juntamente com os serviços pessoais e de recreação, apesar do expressivo volume importado pela França, ainda tem muito para crescer.

Apesar de representar baixo valor no total dos serviços culturais importados, há que se considerar sua importância no montante geral das despesas da conta de serviços em 2007.

\section{AS ATIVIDADES COMERCIAIS DESENVOLVIDAS A PARTIR DA CULTURA}

Para Ribeiro (2008) as atividades culturais de um país em outro favorecem o fortalecimento de um clima de confiança nas qualificações desse país, ou seja, as características de confiabilidade de um determinado produto comercial se vêem grandemente fortalecidas se inseridas no contexto cultural a que pertencem.

A exemplo, o ano do Brasil na França, resultado de um acordo cultural entre os governos dos dois países, a Saison Culturelle de 2005 reuniu projetos brasileiros de teatro, cinema, dança, grupos folclóricos, fotografia, gastronomia, esporte, música, artes plásticas, design e literatura na maior manifestação cultural e artística realizada pelo Brasil no exterior.

Para as empresas brasileiras, que patrocinaram os projetos foi uma oportunidade inédita para expor sua marca e seus produtos no disputado mercado internacional.

O evento foi visitado não apenas pela população francesa, mas também, pelos turistas que visitaram aquele país. Entre 2001 e 2003, cerca de 78 milhões de turistas estrangeiros visitaram anualmente a França (WOOS, 2005).

\section{EVOLUÇÃO COMERCIAL ENTRE FRANÇA E BRASIL}

O evento que iniciou em meados de março e se estendeu até dezembro 2005, já no inicio apresentou resultados nos números do comércio exterior. Somente nos primeiros quatro meses de 2005, as exportações com destino aos portos franceses cresceram 16,7\% em relação ao mesmo período do ano de 2004, chegando a uma soma de US\$ 782 milhões. O país durante o ano de 2004 , ocupou a $10^{a}$ posição entre os países compradores de produtos brasileiros, responsável por cerca de 2,3\% das exportações, ou seja, US\$2,189 milhões. (CAMARA DE COMÉRCIO FRANÇA-BRASIL, 2005).

Além dos resultados surpreendentes nas relações comerciais, o evento mobilizou mais de 15 milhões de pessoas, com centenas de atrações realizadas em todo o território francês, que trouxeram impactos diretos não só para o intercâmbio cultural, mas também para as trocas comerciais entre os dois países. Na ocasião, registrou-se aumento de três vezes no volume de negócios entre França e Brasil em comparação ao ano anterior, o que correspondeu a cerca de US\$ 450 milhões de produtos brasileiros importados pela França em 2005. O governo francês registrou um crescimento de $27 \%$ no movimento de turistas franceses no Brasil, além do crescimento de $20 \%$ nas matrículas nos cursos de português na França (MINISTÉRIO DAS RELAÇÕES EXTERIORES, 2009). 
Em 2009 é a vez do Ano da França no Brasil - França.Br 2009 - que tem como objetivo principal fortalecer a parceria estratégica entre os dois países que ocorre em reciprocidade ao Ano do Brasil na França - Brésil Brésis, realizado em 2005. A exemplo, do que ocorreu no ano do Brasil na França, o evento leva a todas as regiões brasileiras uma série de atrações artísticas e culturais, além de debates e atividades nas diversas áreas do conhecimento, da economia e da tecnologia, com a finalidade de mostrar aos brasileiros as diversas faces da França contemporânea e ampliar as oportunidades de intercâmbio entre os dois países.

O Ano da França no Brasil, que iniciou em março de 2009 e se estende até de dezembro de 2009, mostra o incremento econômico motivado pelo evento, antes mesmo de seu inicio. No mês de janeiro de 2009, as exportações para a França somaram US\$ 264,4 milhões, ante os US\$ 257,9 milhões no mesmo período de 2008, de acordo com levantamento do Ministério do Desenvolvimento, Indústria e Comércio Exterior. Já as importações movimentaram US\$ 303,2 milhões, equilibrando a balança comercial (MINISTÉRIO DAS RELAÇÕES EXTERIORES, 2009).

Nas palavras de Mura (2009) o Ano da França no Brasil chega como uma excelente oportunidade para brasileiros e franceses incrementarem os elos políticos e comerciais estabelecidos historicamente entre os dois países.

\begin{abstract}
Não é só pela diversidade cultural que o Brasil foi escolhido como o grande parceiro da França em 2005 e, agora, transformado em anfitrião. Além de os franceses serem o quarto maior investidor no País, é evidente a reciprocidade nas relações econômicas entre os dois países. O empenho na organização dessa temporada reforça a perspectiva de que os efeitos negativos da turbulência econômica podem ser minimizados com a união das forças que atravessam fronteiras (MURA, 2009).
\end{abstract}

De acordo com o Ministério da Cultura está é uma mobilização sem precedentes na história das relações comerciais franco-brasileiras. Lançado oficialmente em dezembro de 2008, além do enfoque voltado para a cultural, o evento também está voltado para atividades de fomento das relações econômicas e comerciais.

Como está a relação entre Brasil e França em termos de comércio e qual é a posição brasileira enquanto ator da economia mundial?

Conforme Explicação do Chefe da Missão Econômica da França Dominique Mauppin, o Brasil é hoje um dos grandes atores da economia mundial, despontando como principal país emergente entre os 25 mercados prioritários franceses. A presença francesa no Brasil é muito forte, contando com 400 empresas francesas de todos os portes (MINISTÉRIO DA CULTURA, 2009).

De acordo com dados do Ubifrance (2009) as trocas comerciais franco-brasileiras no ano de 2008, atingiram $€ 7.490,00$ bilhões o que representa um acréscimo de $12,8 \%$ em relação ao ano de 2007 que foi de $€ 6.639,00$ bilhões. O Brasil é atualmente o principal parceiro comercial da França dentro da América Latina com um fluxo de 35,8\% do comercio da região. Além de ser o $4^{\circ}$ parceiro comercial da França fora da Organização para a Cooperação e Desenvolvimento Econômico. 


\section{CULTURA COMO ELO DE LIGAÇÃO E FORTALECIMENTO NAS RELAÇÕES INTERNACIONAIS}

Em junho de 1999 foi realizada a I Cúpula entre Chefes de Estado e de Governo da América Latina, Caribe e da União Européia, no Rio de Janeiro, o que refletiu a determinação das regiões de fortalecer suas relações nos campos político, econômicocomercial, cultural, educativo e humano (MINISTÉRIO DAS RELAÇÕES EXTERIORES, 2009).

Desde então, realizaram-se quatro outras reuniões de Cúpula, em Madri (2002), em Guadalajara (2004), em Viena (2006) e em Lima (2008).

Em 2005, aconteceu em Caracas, Venezuela o $14^{\circ}$ Fórum de Ministros da Cultura e Encarregados de Políticas Culturais da América Latina e do Caribe (RELATÓRIOSÍNTESE DO $14^{\circ}$ FÓRUM DE MINISTROS DA CULTURA E ENCARREGADOS DE POLÍTICAS CULTURAIS DA AMÉRICA LATINA E DO CARIBE, 2005) no qual foram discutidos vários temas relativos à Cultura e ao estabelecimento de relações mais estritas entre a América Latina e Caribe. Que contou com as presenças de representantes dos países latino-americanos e caribenhos, entre os quais um brasileiro, além de representante da UNESCO.

No evento o Subsecretário de Estado para a Cultura, a Criatividade e a Participação Popular da República Dominicana Avelino Stanley, salientou que:

[...] adotar decisões em relação ao papel da cultura no fortalecimento dos processos democráticos dos países da região, à integração da cultura como elemento-chave ao planejamento do desenvolvimento dos países, à consecução de indicadores econômicos que mostrem a participação da cultura no Produto Interno Bruto dos países, à promoção de políticas culturais e educativas que coadjuvem a conscientização da necessidade da integração cultural da América Latina e do Caribe, e à aproximação entre os programas educativos e culturais para viabilizar a construção de um espaço cultural latino-americano e caribenho (STANLEY, 2005)

Entre todos os que participaram, houve uma consonância no que tange a cultura como instrumento gerador de possibilidade capaz de propiciar uma mudança qualitativa nas relações humanas, e de contribuir para o desenvolvimento econômico, inclusive para a democratização.

Em 2001, na Conferência das Nações Unidas sobre os Países Menos Avançados, que constituem as 50 economias mais vulneráveis do mundo o tema ganhou destaque. Desde então, as economias criativas, se converteram num dos programas para promover o desenvolvimento de países da África, Ásia, América Latina, Caribe, mediante o pleno aproveitamento do seu potencial cultural em termos de desenvolvimento econômico e social (REIS, 2008).

Durante o $16^{\circ}$ Fórum de Ministros de Cultura e Encarregados de Políticas Culturais da América Latina e Caribe que aconteceu no mês de Fevereiro de 2009 em Buenos Aires, na Argentina. Os participantes do encontro discutiram temas como diversidade cultural, diálogo intercultural, integração regional, papel das indústrias culturais, oportunidades para um desenvolvimento sustentável, direitos culturais e fortalecimento institucional da 
cultura. Na ocasião, ministros de Cultura e responsáveis pela área na América Latina e no Caribe pediram que os países investissem no fortalecimento da diversidade para conter a crise financeira global (TEIXEIRA, 2009).

Os participantes também defenderam que a cultura seja usada como ferramenta transformadora para combater a pobreza e as desigualdades sociais.

Dando continuidade ao tópico buscou-se desenvolver subtópico o primeiro deles detalhando o apoio ao desenvolvimento econômico de órgãos, que visam $o$ desenvolvimento pautado na cultura, o segundo subtópico traz um panorama das relações entre o Brasil e os países do Caribe, em seguida há um outro subtópico relativo a criação do Mercado Comum do Sul - o MERCOSUL, oferecendo uma visão geral das questões culturais dentro do Mercosul.

\section{ÓRGÃOS DE APOIO AO DESENVOLVIMENTO ECONOMICO}

A Fundação Interamericana de Cultura e Desenvolvimento (2008) criada com o objetivo de apoiar projetos de amplo alcance, empreendido pelo Banco Interamericano de Desenvolvimento, agregando uma dimensão privada, única e importante para o desenvolvimento do setor cultural, com estratégias de captação de recursos para apoio de projetos culturais, nos quais possuem impacto no desenvolvimento socioeconômico no caribe e na América Latina. Vem desenvolvendo projeto de apoio à economia criativa, direcionando recursos as diversas áreas que integram a diversidade cultural, na busca de desenvolvimento econômico e manutenção da identidade cultural de cada país.

As indústrias culturais contribuem com o desenvolvimento econômico, geram fontes de empregos e são peças fundamentais para a preservação da identidade cultural dos países do Caribe e da América Latina.

Segundo o Inter-American Culture \& Development Foundation (ICDF) esta área fortalece projetos que contribuem com o incremento de benefícios econômicos e sociais para as indústrias culturais, por meio de gestão de projetos, capacidade de construção, criação, produção e distribuição de bens e serviços culturais nas diversas áreas compreendidas como produção cultural.

Como parte da missão de promover a cultura como produto de desenvolvimento socioeconômico, a Fundação definiu áreas estratégicas:

Sendo elas:

a) Indústrias culturais e turismo;

b) Museus comunitários e regionais;

c) Patrimônio cultural tangível e intangível;

d) Empreendedores sociais e culturais;

e) Cultura e tecnologia da informação para desenvolvimento

Estas áreas estratégicas têm em comum a difusão da cultura. Estando em conexão entre si, as áreas estabelecidas, visão o crescimento econômico conjugado ao desenvolvimento propiciado pela ampla possibilidade que o setor cultural dispõe. 
As tecnologias da Informação e Comunicação sendo parte integrante da chamada economia criativa são fundamentais para o desenvolvimento e acesso ao conhecimento e intercambio de informações entre regiões e países. Sendo ferramentas tecnológicas que preserva e difunde valores, tradições e a diversidade cultural das regiões, fortalecendo e contribuindo para integração e desenvolvimento socioeconômico de comunidades na América Latina no Caribe.

\title{
RELAÇÕES ENTRE O BRASIL E PAÍSES DO CARIBE
}

As relações com os países do Caribe têm sido cordiais, mesmo que de baixa intensidade. Os países caribenhos tradicionalmente foram voltado para os Estados Unidos e, nos últimos anos, estão buscando uma maior aproximação com a América Latina, especialmente com o Mercosul, concedendo oportunidades para a política externa brasileira, levando-se em conta o mercado potencial da região.

Antes de 1992, o Brasil foi um país razoavelmente fechado para mercados externos, de modo que não era apenas com o CARICOM que mantinha um baixo relacionamento comercial.

Para Farias (2000)

\begin{abstract}
O relacionamento entre o Brasil e o Caribe, bem como entre o Brasil e os países membros do CARICOM, tem sido bastante reduzido, especialmente no que diz respeito ao aspecto econômico. Segundo os Embaixadores brasileiros lotados no Caribe e na América Central (em 1994), existe margem para intensificação dos contatos do Brasil com os países da região em praticamente todas as áreas de relacionamento.
\end{abstract}

As relações do Brasil com os países da região caribenha podem ser caracterizadas como cordiais e marcadas por grande potencial de adensamento, sobretudo nas áreas cultural, econômico-comercial e de cooperação para o desenvolvimento. Por outro lado os países do Caribe têm se mostrado crescentemente receptivos a uma presença brasileira mais significativa na região.

As relações do Brasil com alguns países do Caribe têm-se pautado pelo reconhecimento mútuo do potencial para seu estreitamento. O conjunto dos países caribenhos representa um mercado bastante atraente para o Brasil. Tais considerações vêm conduzindo a uma análise pelo Itamaraty dos meios para adensar as relações do Brasil com os países da região, buscando estabelecer meios de integrar as atividades brasileiras na América Central e no Caribe. Diante dessas considerações, o Brasil aderiu à Associação dos Estados Caribenhos (AEC), na qualidade de observador, e tem procurado intensificar o fluxo de visitas recíprocas.

Os países que compões a comunidade caribenha não têm muito poder econômico, mas contam com um grande poder de produção cultural. Como por exemplo, o setor de turismo que é uma das principais fontes de renda, que recebe em media cerca de 15 milhões de turistas por ano. O Caribe tem uma população de 14,6 milhões de habitantes, um PIB de US\$ 28,1 bilhões, exportações girando em torno dos US\$12,6 bilhões e importações 
alcançando os US\$ 15,9 bilhões (CÂMARA DO COMÉRCIO E INDÚSTRIA DO RIO DE JANEIRO, 2009).

Vale ressaltar que os acordos entre o Brasil e os países do Caribe, na grande maioria são acordos bi-laterais. Tendo o Brasil acordos culturais bilaterais com os seguintes países:

- ANTígUA E BARBUdA - Acordo de Cooperação Cultural, Científica e Técnica, 19/07/1996;

- CUBA - Acordo de Cooperação Cultural e Educacional, 03/11/1989;

- HAITI - Convênio de Intercâmbio Cultural, 5/51973;

- REPÚBLICA DOMINICANA - Convênio Cultural, 17/6/1943;

Entre os países da região Cuba apresenta a particularidade do rompimento das relações diplomáticas com o Brasil em 1964, sendo restabelecidas em 1986. Desde então, o relacionamento bilateral entre os dois países apresenta características de constante estreitamento. Os acordos já assinados entre os dois países e as perspectivas concretas de cooperação em setores de interesse comum constituem fator positivo que assinala o processo de consolidação das relações (MINISTÉRIO DAS RELAÇÕES EXTERIORES, 2009).

A partir do ano 2000, inicio-se a fase de conversas entre o Brasil e os países do CARICOM para a formalização de um acordo comercial em 2002.

De acordo com o então ministro do Desenvolvimento, Indústria e Comércio Exterior (2002), a reunião com os embaixadores do Caricom, se concentrou na apresentação da oferta brasileira para a negociação de um acordo de preferências comerciais. Segundo a proposta, o Mercado Comum do Sul (Mercosul), formado pelo Brasil, Argentina, Uruguai e Paraguai, está disposto a fazer uma concessão tarifária linear, e não de produto a produto, de $30 \%$ a $40 \%$, e espera dos países caribenhos uma preferência de $15 \%$ a $20 \%$ (OLIVEIRA, 2002).

As relações econômicas vigentes entre o Brasil e os países do Caribe incluem fluxos comerciais, investimentos culturais e produtivos em ambos os sentidos. Convém salientar que tais relações são influenciadas pelas transformações globais, cujas tendências são favoráveis a uma crescente interdependência comercial e cooperação entre países em desenvolvimento.

\section{CRIAÇÃO DO MERCADO COMUM DO SUL}

O Mercosul surgiu, inicialmente, como zona de livre comércio, estimulada pela liberalização tarifária gradual, linear e automática acordada entre os quatro Estados Membros (Brasil, Argentina, Paraguai e Uruguai).

O Tratado de Assunção, firmado por Brasil, Argentina, Paraguai e Uruguai em 26 de março de 1991, é o instrumento jurídico fundamental do Mercosul (CONGRESSO NACIONAL, 2009). 
A integração comercial propiciada pelo Mercosul também favoreceu a implantação de cooperação nos mais diferentes setores, como educação, justiça, cultura, transportes, energia, meio ambiente e agricultura. Neste sentido, vários acordos foram firmados, entre eles o estabelecimento de protocolos de assistência mútua em assuntos penais e a criação de um "selo cultural" para promover a cooperação, o intercâmbio e a maior facilidade no trânsito aduaneiro de bens culturais.

De acordo com Soares (2008) o tema cultura entrou na agenda do Mercosul no final dos anos 90. A partir de então passou a ser alvo de discussões no Bloco, mas de forma mais retórica do que prática. A cultura, ainda na atualidade, é considerada algo supérfluo e de valor apenas simbólico. Ela não é valorizada nem como um instrumento de aproximação das sociedades nem como facilitadora do avanço da integração regional.

Para Soares (2008) a análise das questões culturais na agenda de negociações do Mercosul resultam algumas conclusões:

1. A posição subordinada dos departamentos ou direções de assuntos culturais no organograma dos ministérios de Relações Exteriores dos países revela a reduzida importância atribuída à cultura na política externa dos países.

2. No Mercosul, a cultura tem sido pouco valorizada e utilizada para o estabelecimento de pontes e relações de confiança entre países que, até recentemente, pouco conheciam-se.

3. A diplomacia cultural dos países do Mercosul, no futuro, crie imagens favoráveis dos respectivos países e aumente a confiança entre eles, ela deverá aumentar a comunicação entre suas populações.

4. O conhecimento da história, da cultura e da economia dos países com os quais pretende-se estabelecer relações de confiança e de cooperação é essencial.

Segundo Soares (2008)

O primeiro passo a ser dado para a criação de uma diplomacia cultural no Mercosul é o reconhecimento, por seus Estados-membros, que a falta do terceiro pilar da integração, que é a cultura, é um grande obstáculo para o avanço do processo de integração. A diplomacia "discursiva" sobre a cultura deve dar lugar a uma diplomacia cultural que utilize a cultura como fator de integração.

Ainda de acordo com Soares (2008) as atividades culturais identificadas em alguns países, como no Brasil, à diplomacia cultural está limita a exposições, feiras, congressos ou outros eventos culturais eventuais ou de curto prazo. Não há políticas culturais relacionadas ao relacionamento entre os países do bloco, nem no âmbito dos ministérios da Cultura nem no de Relações Exteriores.

\section{UNIÃO EUROPÉIA}

Em 2007 o Conselho da União Européia aprovou uma Resolução na qual foram definidas estratégias comuns para os Estados Membros da União Européia em matéria de Cultura: a Agenda Européia para a Cultura. 
Ligada aos desafios da criatividade e da inovação, a cultura desempenha um papel cada vez mais relevante na economia dos Estados Membros, situação comprovada pelos diversos estudos efetuados recentemente, a nível nacional, regional e comunitário, sobre a economia da cultura. A título de exemplo, o importante estudo efetuado pela Comissão Européia em 2006 evidenciou, entre outras coisas, o significativo e crescente impacto econômico do setor cultural (CAMARA DO COMÉRCIO E INDÚSTRIA DE PORTUGAL, 2007).

A Agenda Européia para a Cultura (2007) identifica três grandes objetivos estratégicos, que são no mesmo documento detalhados em objetivos específicos:

- Promoção da diversidade cultural e do diálogo intercultural;

- Promoção da cultura como catalisador da criatividade no âmbito da Estratégia de Lisboa para o crescimento, o emprego, a inovação e a competitividade;

- Promoção da cultura como elemento vital nas relações internacionais da União.

O Parlamento Europeu, em 2007 lançou proposta para sobre as indústrias culturais no quadro da Estratégia de Lisboa, destacando pontos para a promoção e desenvolvimento da indústria cultural. Entre esses pontos está:

- Convenção da Organização das Nações Unidas para a Educação, Ciência e Cultura (UNESCO) sobre a proteção e a promoção da diversidade das expressões culturais, de 20 de Outubro de 2005;

- A comunicação da Comissão sobre uma agenda européia para a cultura num mundo globalizado.

Na proposta a cultura é considerada tanto como um bem público e um fim em si para o desenvolvimento do indivíduo e da sociedade, como um instrumento que contribui para o crescimento econômico, o emprego e também para a coesão social e o desenvolvimento regional e local, como o demonstram estudos científicos recentes. Não deixando de observar, no entanto, que é necessário um maior reconhecimento e um maior apoio para auxiliar as indústrias culturais e criativas a dar todo a sua contribuição para os objetivos da Estratégia de Lisboa (BONO, 2007).

Tal proposta foi lançada após estudo que demonstrou o setor cultural como contribuinte econômico, com cerca de 2,6 \% para o PIB da União Européia em 2003, com um crescimento consideravelmente mais elevado do que o da economia em geral. Além número de pessoas que trabalhavam no setor da cultura em 2004, mais de cinco milhões de pessoas, o que equivale a $3,1 \%$ do total da população ativa da União Européia (BONO, 2007).

O estudo também constatou que além da contribuição econômica direta o setor cultural tem um impacto indireto no ambiente socioeconômico europeu, promovendo a inovação em outros setores da economia.

As indústrias criativas, sendo ela também composta pela indústria da cultura, estão liderando o crescimento econômico, o emprego e o comércio. Na Europa, gerou um faturamento de $€ 654$ milhões, crescendo $12 \%$ mais rapidamente do que a economia total e empregando cerca de 4,7 milhões de pessoas em 2004. No Reino Unido ela é responsável por um em cada cinco empregos em Londres, contribuindo com £11,4 bilhões para a 
balança comercial do Reino Unido, razão pela qual o governo do país decidiu transformar a sua capital no centro criativo do mundo. A Dinamarca é outro exemplo notável em que a economia criativa representou 5,3\% do PIB, provendo $12 \%$ do número total de empregos e representando $16 \%$ do total de exportações (REIS, 2008).

\section{RELACIONAMENTO BRASIL E UNIÃO EUROPEIA}

A União Européia (UE) tem um programa de Cooperação Cultural (MINISTÉRIO DA CULTURA, 2009) que foi lançado no ano 2000. Em 2004 lança o edital de cooperação com a Rússia, o primeiro país fora da UE, em seguida o Japão nos anos de 2005 e 2006, após o Japão foi a vez da China e Índia de 2007 à 2009. O Brasil foi selecionado este ano para fazer parte do Programa de Cooperação Cultural da União Européia e está disponibilizando $€ 1$ milhão (de Euros) para projetos culturais. $O$ edital foi lançado em 2008 onde o maior objetivo a cooperação cultural que proporcionem intercâmbios culturais de acordo com Programa de Cooperação Cultural - União Européia (MINISTÉRIO DA CULTURA, 2008).

\section{PORTUGAL}

De acordo com a nota estatística do Gabinete de Pesquisa e Estatística, Avaliação e Relações Internacionais (GPEARI) de março de 2008, que teve como base A Economia da Cultura na Europa e foi apresentado pela Direção Geral da Educação e Cultura da Comissão da União Européia que, para efeitos metodológicos, definiu o seguinte que:

- O setor cultural integra as artes tradicionais (artes visuais, de representação e patrimônio) e as indústrias culturais (edição, cinema, música, vídeo games, televisão e rádio)

- O setor criativo que usa a cultura como recurso para produzir bens não culturais, compreende a moda, o design, arquitetura e publicidade.

Trata-se de um estudo inovador que, pela primeira vez, compara o contributo das indústrias culturais e criativas para a economia nacional (portuguesa) e européia (GPEARI, 2008).

Estudo referente à Economia da Cultura na Europa apresentado pela Direção Geral da Educação e Cultura da Comissão da União Européia que, para efeitos metodológicos, apresenta alguns dados que estão na tabela a seguir: 
Tabela 4 - Taxa de Crescimento do setor cultural na União Européia e Portugal

\begin{tabular}{|c|c|c|c|c|c|}
\hline \multicolumn{6}{|c|}{$\begin{array}{l}\text { TAXA DE CRESCIMENTO DO SETOR CULTURAL E CRIATIVO DE } 1999 \text { A } \\
2003\end{array}$} \\
\hline & $\begin{array}{l}\text { Crescimento } \\
\text { Médio do } \\
\text { Volume de } \\
\text { Negócios } \\
\text { (1999-2003) }\end{array}$ & $\begin{array}{c}\text { Crescimento } \\
\text { Médio do } \\
\text { VAB para o } \\
\text { PIB (1999- } \\
\text { 2003) }\end{array}$ & $\begin{array}{l}\text { Volume de } \\
\text { negócios } \\
\text { (milhões de } \\
\text { euros) } 2003\end{array}$ & $\begin{array}{c}\text { Valor } \\
\text { acrescentado } \\
\text { do setor para o } \\
\text { PIB (\%) } 2003\end{array}$ & $\begin{array}{c}\text { Emprego } \\
\text { (\% total) } \\
2003\end{array}$ \\
\hline UE & 5.4 & 6.6 & 636.146 & 2,6 & 2,5 \\
\hline PORTUGAL & 10.6 & 6.3 & 6.358 & 1,4 & 1,4 \\
\hline
\end{tabular}

Fonte: Estudo A economia da Cultura na Europa GEPEARI, 2008

A tabela 4 mostra a contribuição econômica real e significativa, proporcionada pelo setor da cultura na EU e em Portugal. O setor cultural e criativo demonstra grande dinamismo na União Européia, com o volume de negócios crescente, em média, 5,4\% e 6,6\% por ano, entre 1999 e 2003. O mesmo dinamismo é registrado em Portugal, onde o volume de negócios registra taxas de crescimento acima dos 10\% (GABINETE DE PLANEJAMENTO, ESTRATÉGIA, AVALIAÇÃO E RELAÇÕES INTERNACIONAIS, 2008).

\section{FRANÇA}

De acordo Tolila (2007) na França, em 2002, o consumo cultural doméstico em bens e serviços culturais era de $€ 38,150$ bilhões de euros, o que equivale a 4,6\% do consumo doméstico total. $\mathrm{O}$ conjunto da receita das atividades culturais, segundo seus financiamentos, chegava a $€ 62,503$ bilhões de euros, ou $4 \%$ do PIB. No interior desse volume global de receita, as respectivas partes dos diferentes atores do financiamento se dividiam da seguinte forma (em ordem decrescente): famílias: 61\%; coletividades públicas: 24,3\% (dos quais 16,9\% do Estado e 7,4\% de coletividades regionais); empresas: $14,7 \%$ (dos quais $0,3 \%$ em mecenato e $14,4 \%$ em gastos com publicidade).

A economia criativa vem se apresentando como propulsor econômico e desenvolvimentista, o ano de 1997 é um marco inicial da sua contribuição, quando a GrãBretanha as atividades culturais ganharam status de indústria (ADMINISTRADORES, 2008). 


\section{GRÃ-BRETANHA}

Em 1997, a Grã-bretanha desenvolveu uma ampla análise de estudo dos diferentes setores econômicos, após constatar a falência de seu modelo manufatureiro identificou o setor cultural como fonte econômica substituta.

Foi justamente através das indústrias criativas, que a Grã-bretanha lançou seus investimentos na indústria da cultura. Desde então, o setor vem se desenvolvendo, contribuindo para o crescimento da economia. Entre os anos de 1997 e 2000, por exemplo, a taxa de crescimento das indústrias criativas foi de $7,9 \%$ do PIB, contra $2,8 \%$ da economia. Em 2000, o setor rendeu $£ 8,7$ bilhões em exportações. Outro fator positivo encontrado pela Grã-Bretanha foi o combate ao desemprego, que atinge a economia européia, por meio da industria da cultura. Entre 1997 e 2001, o emprego nas indústrias criativas teve uma taxa média de crescimento de 5\% ao ano, representando 1,95 milhão de empregos em 2000 (BRASIL CULTURA, 2009).

\section{CONSIDERAÇÕES FINAIS}

A Economia da Cultura é hoje um setor estratégico, já responsável por 7\% do PIB global, segundo estimativa do Banco Mundial. As atividades culturais constituem atualmente um dos setores mais dinâmicos da economia mundial, com impactos significativos e crescentes sobre a geração de renda e emprego como também sobre a formação do capital humano das sociedades.

De acordo com esse estudo, trata-se de um dos setores que mais cresce, mais emprega e melhor paga em diversos países, superando setores mais tradicionais da economia. Indo além, por estar pautado em criação e propriedade intelectual, os bens e serviços culturais vem se posicionando, como ator principal da chamada economia do conhecimento, integrando um dos segmentos mais dinâmicos e atrativos da economia contemporânea.

O setor criativo contribui com outros setores indiretamente e de forma significativa como, por exemplo, para o desenvolvimento das tecnologias da informação e da comunicação, desempenhando um papel importante, revelando-se essencial para assegurar um desenvolvimento sustentável.

O caso brasileiro da cultura tem como um dos fatores positivo o vasto potencial para ser desenvolvido na produção e distribuição de bens e produtos culturais. Conforme argumentado anteriormente, o Brasil tem evidente vocação para fazer da Economia da Cultura um vetor de desenvolvimento, pela força e diversidade Cultural, que deve ser entendida como um grande ativo do país, que se tratado devidamente, pode contribuir decisivamente para o crescimento do Brasil, assim como para a qualificação deste crescimento.

Ressaltando-se ainda as relações comerciais desenvolvidas a partir de relações culturais que se mostram eficientes no que tange a promoção da imagem e promoção comercial dos países envolvidos, como prova disso temos o aumento das negociações comerciais entre Brasil e França, desenvolvidas após o intercambio cultural entre os dois países em 2005, no 
Ano do Brasil na França, e que está se repetindo em 2009, com o Ano da França no Brasil, o que contribui substancialmente para o aumento das transações realizadas pelo Brasil com aquele país.

O reconhecimento da cultura como fonte de geração econômica e emprego, é recente, conforme relatos desse trabalho. A economia da cultura tem como base produtiva a produção e circulação de bens e serviços pautada na propriedade intelectual, o que extrapola os paradigmas da economia tradicional. É sabido que a produção de cultura apresenta potencial de desenvolvimento e qualificação na geração de riqueza e de inserção qualificada no cenário do comercio internacional.

A Grã-bretanha foi uma das primeiras regiões a identificar o setor cultural como fonte econômica substituta de seu modelo manufatureiro.

Com esse estudo foi possível constatar que a produção cultural brasileira, apesar do reconhecimento de sua importância, que vai além de sua representatividade simbólica e social, é ainda muito incipiente no sentido de ser considerado como um setor altamente produtivo, gerador de emprego e renda. Como já está sendo considerado em países da União Européia.

A ausência de estudos voltados a produção cultural causa uma lacuna a ser preenchida, com a finalidade de objetivar e diminuir o gargalo na produção, distribuição e capitalização do setor cultural.

Em se tratando das relações do Brasil com os países do Caribe e do Mercosul, percebeu-se durante o desenvolvimento do trabalho a preocupação de organismos internacionais no desenvolvimento e promoção cultural, com estratégias de captação de recursos para apoio de projetos culturais, nos quais possuem impacto no desenvolvimento socioeconômico no caribe e na América Latina, desenvolvendo projeto de apoio à economia criativa, direcionando recursos as diversas áreas que integram a diversidade cultural, na busca de desenvolvimento econômico e manutenção da identidade cultural de cada país.

As indústrias culturais contribuem com o desenvolvimento econômico, geram fontes de empregos e são peças fundamentais para a preservação da identidade cultural dos países do Caribe e da América Latina.

No que diz respeito a contribuição na balança de serviços, foi percebido que nas negociações do Brasil com países onde a relação cultural é mais intensa, como as relações do Brasil com alguns dos países da UE, houve um melhor desempenho, comprovando que a cultura deve ser tratada e reconhecida como meio de promoção da imagem e estreitamento das relações não só culturais, como também comerciais.

Em suma, podemos concluir que a cultura é uma forte aliada ao desenvolvimento econômico, ocupando em alguns países posição de destaque na geração de emprego e renda, e tratada como substituta de setores industriais, que até pouco tempo eram os principais meios de produção e geração de riqueza desses países, como também um bem que agrega valor aos produtos produzidos, favorecendo a criação de uma boa imagem para o país. 
E finalizando esse trabalho, a pesquisadora propõe o prosseguimento da pesquisa, considerando que esse é um campo com muito a ser explorado e para isso sugerindo as seguintes pesquisas:

-Estudo a respeito da Cadeia produtiva da economia do Carnatal, mapear as diferentes atividades do setor e identificar desafios e traçar diretrizes para desenvolver e solidificar o evento como negócio.

- Estudo de caso - investimento de empresas da Grande Natal em produtos culturais como promoção da imagem da empresa.

- Desenvolvimento regional promovido pelo investimento cultural.

- O poder econômico gerado pela produção cultural de massa e suas consequiências face ao desenvolvimento.

- Diplomacia e relações econômicas: a influência da cultura.

\section{REFERÊNCIAS BIBLIOGRÁFICAS}

1. ADMINISTRADORES. Viva a economia criativa. 2008. Disponível em: <http://www.administradores.com.br/noticias/viva_a_economia_criativa/14062/> Acesso em: 11 maio 2009.

2. AGENDA EUROPEIA PARA A CULTURA. Programa Cultura 2007-2013. Disponível em:

< http://www.gpeari.pt/> Acesso em 12 maio 2009.

3. CAMARA DO COMÉRCIO E INDÚSTRIA DE PORTUGAL. Primeira estratégia europeia para a cultura, 2007. Disponível em:

$<$ http://www.aeportugal.pt/Inicio.asp?Pagina=/Aplicacoes/Noticias/Noticia\&Codigo=9 935> Acesso em: 02 jun. 2009.

4. AYERBE, Luis Fernando. Cultura e hegemonia na nova ordem mundial. En publicacion: O Ocidente e o "Resto". A América Latina e o Caribe na cultura do Imperio, 2003. Disponível em:

<http://bibliotecavirtual.clacso.org.ar/ar/libros/ayerbe/capituloI.pdf> Acesso em: 07 nov.2008.

5. Banco Central do Brasil. Setor Externo. nota para a imprensa - 2009. Disponível em: <http://www.bcb.gov.br/?ECOIMPEXT> Acesso em: 21 maio 2009.

6. BERTINI, Alfredo. Economia da Cultura: a indústria do entretenimento e o audiovisual no Brasil. Saraiva. São Paulo, 2008.

7. BONO, Guy. Projecto de relatório sobre as indústrias culturais no quadro da estratégia de Lisboa: Comissão da Cultura e da Educação. Parlamento Europeu. Lisboa, 2007. Disponível em:

<http://www.europarl.europa.eu/meetdocs/2004_2009/documents/pr/684/684266/6842 66pt.pdf> Acesso em: 03 mar. 2009.

8. BRAGA, Isabel Abreu. Fórum internacional de economia criativa. São Paulo, 2007. Disponível em: 
<http://planetasustentavel.abril.com.br/noticia/eventos/conteudo_261701.shtml> Acesso em: 25 maio 2009.

9. BRASIL CULTURA. Atividade econômica. Disponível em: $<$ http://www.brasilcultura.com.br/conteudo.php?menu=90\&id=1838\&sub=1910> Acesso em: 11 nov.2008.

10. Economia da cultura 3,2009 . Disponível em:

<http://www.brasilcultura.com.br/cultura/economia-da-cultura-3/> Acesso em: 13 jun. 2009.

11. CÂMARA DO COMÉRCIO E INDÚSTRIA DO RIO DE JANEIRO. Comunidade do Caribe. Disponível em:

$<$ http://www.caerj.org.br/index.php?option=com_content\&view=article\&id=59\&Itemi $\mathrm{d}=79>$ Acesso em: 05 maio 2009.

12. CAMARA DE COMÉRCIO FRANÇA-BRASIL. Ano do Brasil na França alavanca exportações em 2005. Disponível em: < http://www.ccfb.com.br/sobre/ano.html> Acesso em: 17 maio 2009.

13. CONGRESSO NACIONAL. Comissão parlamentar conjunta do mercosul: representação brasileira. Disponível em:

<http://www.camara.gov.br/mercosul/blocos/CARICOM.htm> Acesso em: 10 mar.2009.

14. CONSULADO GERAL DA FRANÇA EM SÃO PAULO. Ano da França no Brasil. Disponível em: < http://www.ambafrance.org.br/saopaulo> acesso em: 12 abr. 2009.

15. FANCHIN, Odília. Fundamentos de metodologia. 4 ed. Saraiva. São Paulo, 2003.

16.FARIAS, Déborah Barros Leal. O Brasil e o CARICOM. Revista Brasileira de Política Internacional, v.43 n.1 Brasília, Jan./Jun 2000. Disponível em:

<http://www.scielo.br/scielo.php?pid=S0034-

73292000000100003\&script=sci_arttext> Acesso em: 15 mar. 2009.

17. FIORI, Mylena. Gatt, a pré-história da OMC. 2005. Disponível em:

<http://www.radiobras.gov.br/materia_i_2004.php?materia=226621\&q=1> Acesso em: 10 jun. 2009.

18. GABINETE DE PLANEJAMENTO, ESTRATÉGIA, AVALIAÇÃO E RELAÇÕES INTERNACIONAIS. Estudo A Economia da Cultura. Portugal, 2008. Disponível em: <http://www.gpeari.pt/> Acessado em: 16/03/2009.

19. em: 16 mar. 2009.

Nota Estatística, 2008. Disponível em: < http://www.gpeari.pt/> acesso

20. GIL, Antonio Carlos. Como elaborar projetos de pesquisa. 4 ed. Atlas. São Paulo, 2002.

21. INSTITUTO BRASILEIRO DE GEOGRAFIA E ESTATÍSTICA. Estudos e Pesquisas Informação Demográfica e Socioeconômica Sistema de Informações e Indicadores Culturais 2003. N 18. Rio de Janeiro, 2006

22. Estudos e Pesquisas Informação Demográfica e Socioeconômica Sistema de Informações e Indicadores Culturais 2003 - 2005. N 22. Rio de Janeiro, 2007

23. Indicadores de desenvolvimento sustentável. Rio de Janeiro, 2002. 
24. Indicadores de desenvolvimento sustentável. Rio de Janeiro, 2009.

25. INTER-AMERICAN CULTURE \& DEVELOPMENT FOUNDATON. Alliances in Action. 2008. Disponivel em:

$<$ http://www.iacdf.org/index.php?option=com_content\&view=article\&id=105\&Itemid $=41>$ Acesso em: 28 maio 2009 .

26. INTERNATIONAL CENTRE FOR TRADE AND SUSTAINABLE DEVELOPMENT. UNESCO Aborda relação entre cultura e comércio. 2007 Disponível em: http://ictsd.net/i/news/4411/> Acesso em: 08 nov. 2008.

27. INFORME MUNDIAL SOBRE A CULTURA, 2000: diversidade cultural, conflito e pluralismo. São Paulo: Brasília: Moderna; Unesco, 2004. 416 p. Tradução de: World culture report 2000: cultural diversity, confl ict and pluralism.

28. LABOISSIÈRE, Paula. Parcerias com ONG podem facilitar promoção dos direitos humanos, mostra estudo. Agência Brasil. Disponível em:

<http://www.agenciabrasil.gov.br/noticias/2008/11/12/materia.2008-

1112.5351945022/view> Acesso em: 15 dez. 2008.

29. LATOEIRA, Cristina. Indústrias criativas: mapeamento, organização estudos de caso. Departamento de Prospectiva e Planeamento e Relações Internacionais. Portugal, 2007. Disponível em: <http://www.dpp.pt/pages/files/Industrias_Criativas.pdf> Acesso em: 23 maio 2009.

30. LEITÃO, Sérgio Sá. Economia da cultura e indústrias culturais. 2007. Disponível em: <http://www.pacc.ufrj.br/z/ano3/03/saleitao.htm> Acesso em: 10 maio 2009.

31. LIMA, Antonio A. Dayrell de. Diversidade Cultural. 2003. Disponível em: $<$ http://portal.unesco.org/en/ev.php-

URL_ID=10238\&URL_DO=DO_TOPIC\&URL_SECTION=201.html> Acesso em: 10 jun. 2009. Não paginado.

32. MARTINS, Maria Helena Pires. Papos culturais. Disponível em:

<http://paposculturais.blogspot.com/2007/06/falando-do-conceito-de-cultura.html> Acesso em: 30 nov. 2008.

33. MATOSO, Rui. Cultura, Economia e Desenvolvimento. 2006. Disponível em: <http://www.culturaviva.com.pt/textos/rui\%20matoso/Artigo1_Rui\%20Matoso.pdf> Acesso em: 31 ago. 2008.

34. MELO, Marcelo Mário de. A Hora e a vez da economia da cultura. Disponível em: $<$ http://www.fundaj.gov.br/notitia/servlet/newstorm.ns.presentation.NavigationServ let?publicationCode $=16 \&$ pageCode $=377 \&$ textCode $=10437 \&$ date $=$ currentDate $>$ Acesso em: 11 nov. 2008.

35. MINISTÉRIO DA CULTURA. Ano econômico da França no Brasil fortalecerá parcerias comerciais: Brasil poderá fazer ainda mais parcerias e agregar knowhow de mercado principalmente nos setores estratégicos de desenvolvimento econômico e social. 2009. Disponível em:

$<$ http://anodafrancanobrasil.cultura.gov.br/br/2009/05/07/ano-economico-da-franca-nobrasil-fortalecera-parcerias-comerciais/> Acesso em: 02 jun. 2009.

36.

Programa de cooperação cultural. Disponível em:

<http://www.cultura.gov.br/site/2008/04/10/uniao-europeia-contempla-o-brasil-com-1milhao-de-euros-para-projetos-culturais/> Acesso em: 20 maio 2009. 
37. Acordo MinC/GDF para o Mais Cultura, 2009. Disponível em: <http://www.cultura.gov.br/site/2009/06/01/acordo-mincgdf-para-o-mais-cultura/> Acesso em: 10 jun. 2009.

38. MINISTÉRIO DAS RELAÇÕES EXTERIORES. Ano da França no Brasil. 2009. Disponível em:

<http://www.ambafrance.org.br/cultural/pdf/Release\%20Ano\%20da\%20Fran\%E7a\%2 0no\%20Brasil\%20-\%20final.pdf> Acesso em: 02 jun. 2009.

39. MINISTÉRIO DO DESENVOLVIMENTO, INDÚSTRIA E COMÉRCIO EXTERIOR: Secretaria de Comércio e Serviços, Departamento de Políticas de Comércio e Serviços. Panorama do comércio internacional de serviços. Brasília, 2008. Ano 3, n 1.

40. MURA, Michel Duran. Um leque de oportunidades é aberto no Ano da França no Brasil. Gazeta Mercantil - 04 maio 2009. Disponível em: <https://conteudoclippingmp.planejamento.gov.br/cadastros/noticias/2009/5/4/umleque-de-oportunidades-e-aberto-no-ano-da-franca-no-brasil> Acesso em: 10 jun. 2009.

41. OLIVEIRA, Priscila de. Brasil e Caricom iniciam negociações de acordo comercial. Ministério do Desenvolvimento, Indústria e Comércio Exterior. Brasília, 2002. Disponível em:

<http://www.mdic.gov.br/sitio/interna/noticia.php?area=5\&noticia=4822> Acesso em: 19 maio 2009.

42. PROGRAMA DAS NAÇÕES UNIDAS PARA O DESENVOLVIMENTO. The Creative Economy Report 2008. Disponível em:

$<$ http://translated.dexigner.com/pt/product/news-g14771.html> Acesso em: 10 maio 2009.

43. PORTA, Paula. Economia da cultura: um setor estratégico para o país. Disponível em:<http://www.cultura.gov.br/site/2008/04/01/economia-da-cultura-um-setorestrategico-para-o-pais/> Acesso em 21 ago. 2008.

44. RÊGO, Elba Cristina Lima. Do Gatt à OMC: O que mudou, como funciona e para onde caminha o sistema multilateral de comércio. Disponível em:

<http://www.bndes.gov.br/conhecimento/revista/gatt.pdf> Acesso em: 02 jun. 2009.

45. REIS, Ana Carla Fonseca. Economia Criativa como estratégia de desenvolvimento: uma visão dos países em desenvolvimento/ organização Ana Carla Fonseca Reis. São Paulo. Itaú Cultural, 2008.

46. Economia da cultura e desenvolvimento sustentável: 0 caleidoscópio da cultura. Manole. Barueri, 2007.

47. RELATÓRIO-SÍNTESE DO 14 FÓRUM DE MINISTROS DA CULTURA E ENCARREGADOS DE POLÍTICAS CULTURAIS DA AMÉRICA LATINA E DO CARIBE. Caracas Venezuela, 2005. Disponivel em: <www.lacult.org/docc/Sintesis_informe_Relatoria_primer_dia_por.doc> Acesso em: 29 maio 2009.

48. RIBEIRO, Edgard Telles. Cultura - vertente submersa das relações internacionais. Palestra na UFRJ. Rio de Janeiro, 2008.

49. RUIZ, J. P. Cultural Development, Public Policies and Local Strategies. In: Local Cultural Strategies Development in South-East Europe, Building on Practice and 
Experience. Background paper. Policies for Culture Regional Workshop. Bucareste, 810 Maio, 2003.

50. SÃO PAULO, SECRETARIA DE DESENVOLVIMENTO. Fórum discute Economia Criativa. São Paulo, 2007. Disponível em:

<http://www.desenvolvimento.sp.gov.br/noticias/?ID=754> Acesso em: 14 maio 2009.

51. SILVA, Frederico A. Barbosa. Economia e política cultural: acesso, emprego e financiamento. Brasília, 2007. Coleção cadernos de Políticas Culturais V. 3.

52. SINGER, Paul. Aprender economia. Editora Contexto. São Paulo, 2002.

53. SOARES, Maria Susana Arrosa. A diplomacia cultural no Mercosul. Revista brasileira política internacional. Brasília, 2008. V.51, n 1.

54. STANLEY, Avelino. Relatório-síntese do $\mathbf{1 4}^{\mathbf{0}}$ fórum de ministros da cultura e encarregados de políticas culturais da América Latina e do Caribe. Caracas, 2005. Disponível em:

$<$ www.lacult.org/docc/Sintesis_informe_Relatoria_primer_dia_por.doc> Acesso em: 29 maio 2009.

55. TEIXEIRA, Carina. Ministros defendem investimentos contra a crise. 2009. Disponível em: <http://www.culturaemercado.com.br/post/ministros-defendeminvestimento-contra-crise/> Acesso em: 13 jun. 2009.

56. TOLILA, Paul. Cultura e Economia : problemas, hipóteses, pistas. Tradução Celso M. Pacionik. Iluminuras : São Paulo, 2007. Itaú Cultural.

57. TRIBUNA DA COSTA. Brasil deve investir o dobro para atrair turistas franceses. 2008. Disponível em: < http://tribunadacosta.cidadesol.com> Acesso em: 12 mar. 2009.

58. UBIFRANCE. Et Les Missions Économiques. Relações econômicas, 2009. Disponível em: <http://www.ubifrancebrasil.com.br/relacoes_economicas.asp> Acesso em: 10 jun. 2009.

59. ORGANIZAÇÃO DAS NAÇÕES UNIDAS PARA A EDUCAÇÃO, A CIÊNCIA E A CULTURA. World Commission on Culture and Development. Relatório Our Creative Diversity. França, 1996. Disponível em: <http://unesdoc.unesco.org/images/0010/001055/105586e.pdf> Acesso em: 25 abr. 2009.

60. _. Dia Mundial da Diversidade Cultural para o Dialogo e

Desenvolvimento 2008. Disponivel em<

http://www.brasilia.unesco.org/unesco/premios/DiaDiversCultural2008> acesso em: 06 dez. 2008.

61. VECCHIATTI, Karin. Três fases rumo ao desenvolvimento sustentável: do reducionismo à valorização da cultura. São Paulo, 2004. Disponível em: <http://www.scielo.br/scielo.php?script=sci_arttext\&pid=S010288392004000300010> Acesso em: 12 dez. 2008.

62. WOOS. Brasil levará 400 projetos culturais para a França em 2005. Disponível em: <http://www.wooz.org.br/culturabrasilnafranca.htm 